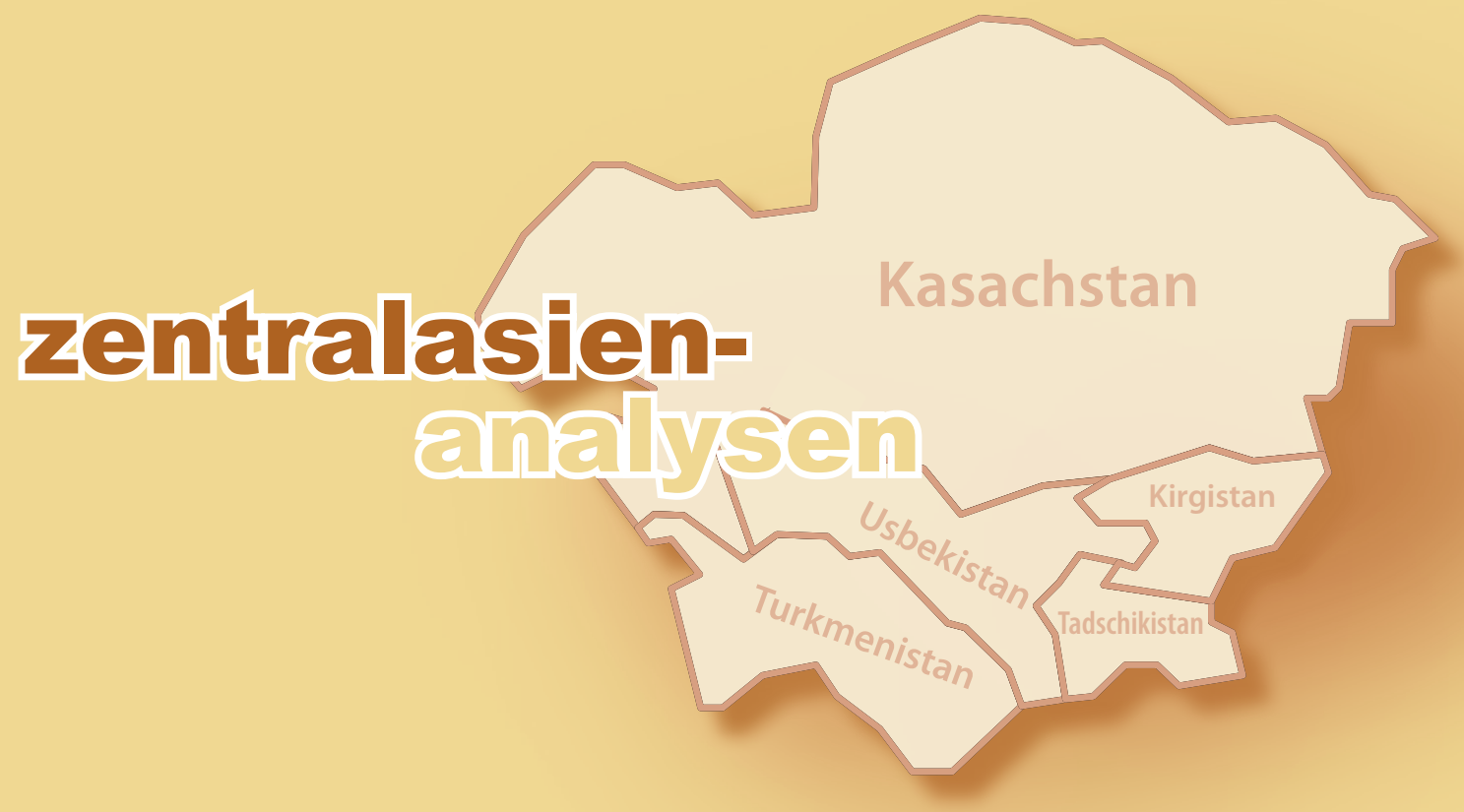

\title{
DIE JUGEND KASACHSTANS, USBEKISTANS UND KIRGISTANS IM DIGITALEN ZEITALTER ISLAM IN USBEKISTAN

ANALYSE

Zwischen Internetkontrolle und Medienkompetenz.

Die Jugend Kasachstans, Usbekistans und Kirgistans im digitalen Zeitalter

Von Marina Zhir-Lebed, Berlin

- STATISTIK

Internetnutzer in Zentralasien

ANALYSE

Halbmondfinsternis.

Aufstieg und Niedergang des Islam in Usbekistan seit dem Ende der Sowjetunion Von Jesko Schmoller, Perm

\section{DOKUMENTATION}

Die »einflussreichste Frau der Welt« zu Besuch in Kirgistan

\section{CHRONIK}

25. Juni - 22. Juli $2016 \quad 18$

$\begin{array}{lr}\text { Kasachstan } & 18\end{array}$

$\begin{array}{lr}\text { Kirgistan } & 20\end{array}$

$\begin{array}{ll}\text { Tadschikistan } & 22\end{array}$

$\begin{array}{ll}\text { Turkmenistan } & 25\end{array}$

$\begin{array}{lr}\text { Usbekistan } & 26\end{array}$

\footnotetext{
Forschungsstelle Osteuropa an der Universität Bremen

- Deutsche Gesellschaft für Osteuropakunde e.V.
} 


\title{
Zwischen Internetkontrolle und Medienkompetenz. Die Jugend Kasachstans, Usbekistans und Kirgistans im digitalen Zeitalter
}

\author{
Von Marina Zhir-Lebed, Berlin
}

\section{Zusammenfassung}

Das Internet hat in den letzten zehn Jahren auch Zentralasien durchdrungen und ist nun für breite Bevölkerungsschichten zugänglich, wobei insbesondere die Jugend von diesem Angebot Gebrauch macht. Das stellt die autoritären Regierungen Kasachstans und Usbekistans, aber auch die kirgisische Führung, vor neue Herausforderungen. Häufig wird die strenge Kontrolle des Internets mit dem Schutz der Jugend gerechtfertigt. Online-Kriegspropaganda und IS-Rekrutierungskampagnen in den sozialen Medien dienen als Rechtfertigung für eine verstärkte Kontrolle des Netzes. Zugleich wird in politischen Diskussionen häufig Medienkompetenz von jungen Menschen als wichtiger Schutzmechanismus erwähnt. Die zahlreichen diesbezüglichen nationalen Programme erscheinen jedoch aufgrund fehlender technischer Ausstattung, insbesondere in den Schulen im ländlichen Raum kaum realisierbar und man kann nicht ausschließen, dass sie nur schöne Fassade vor tatsächlicher Internetzensur sind.

$\mathrm{T}$ rotz der weltweiten Verbreitung global vernetzter Informationsmöglichkeiten kann man heute klar feststellen: Das Internet schafft die nationalen Grenzen nicht $a b$ und die Welt ist bis jetzt noch kein "globales Dorf ". Vielmehr hat die Cyberwelt sich selbst nationalisiert, so dass sich heute parallel zu globalen Tendenzen viele Diskrepanzen in der lokalen Internetentwicklung und -nutzung offenbaren. Die regionale Internetspezifik, die unter anderem technische, rechtliche und inhaltliche Aspekte betrifft, kann darüber hinaus als Indikator der innenpolitischen und gesellschaftlichen Trends in einem Staat oder einer Region betrachtet werden. Da sich weltweit der zweitgrößte Anteil aller Internetnutzer in der Altersgruppe zwischen 15 und 24 Jahre befindet und sich das Internet als ein vergleichsweise »junges Medium« präsentiert, scheint es wichtig, den (beschränkten) Zugang zum Internet in Hinsicht auf junge Menschen zu betrachten. Im Folgenden wird daher versucht, den Umgang mit dem globalen Netz in den drei zentralasiatischen Staaten mit der größten Zahl von Internetnutzern - Kirgistan, Kasachstan und Usbekistan - unter dem Blickwinkel des Jugendmedienschutzes zu beleuchten.

\section{Internetentwicklung in Zentralasien}

Das World Wide Web kam in der Mitte der 1990er Jahre nach Zentralasien. In dieser Zeit entstanden die ersten Websites mit den lokalen Domain-Namen .kz, .kg, .uz u. a., der Internetzugang war jedoch aufgrund der Kosten und der fehlenden Infrastruktur stark eingeschränkt der Anteil der Internetnutzer an der Bevölkerung betrug im Jahr 2000 in Kirgistan etwa 1\%, in Kasachstan $0,7 \%$ und in Usbekistan lag er sogar nur bei $0,5 \%$.

Im Laufe der folgenden zehn Jahre änderte sich diese Situation jedoch in allen drei Ländern drastisch. Die Zahl der Internetnutzer stieg um das Tausendfache.
Immer mehr Internetanbieter kamen auf die lokalen ITMärkte, allerdings hatten die nationalen Telekommunikationsunternehmen KazakhTelecom, UzTelecom und KyrgyzTelecom ein Monopol auf Verteilung der Lizenzen für private Dienstleister sowie auf die Festlegung der Preise und den Aufbau der technischen Infrastruktur. Dank der kolossalen Ressourcen dieser Staatsunternehmen lief der Ausbau der Breitband- und Mobilfunkinfrastruktur vergleichsweise schnell und konnte den Internetzugang zuerst in den großen Städten und privaten Haushalten, wenig später aber auch in einigen ländlichen Regionen und staatlichen Einrichtungen wie Schulen, Universitäten, Bibliotheken etc. sicherstellen. Andererseits erlaubte die monopolisierte Struktur des Informations- und Kommunikationssektors die totale technische Kontrolle des Internetzugangs seitens des Staates. Neue rechtliche Richtlinien wie auch die Anpassung vorhandener Gesetze stellten weitere staatlichen Kontrollmöglichkeiten sicher.

Auf die neuen Möglichkeiten reagierten zuerst die jungen Menschen, die sofort den größten und aktivsten Anteil aller Internetnutzer bildeten. In Kirgistan gehörten im Jahr $201059 \%$ aller Internetnutzer zur Altersgruppe zwischen 16 und 29 Jahren, die zu dem Zeitpunkt wiederum $40 \%$ der Gesamtbevölkerung stellte. Eine ähnliche Tendenz ließ sich in Kasachstan und in Usbekistan beobachten: $66 \%$ der aktiven Internetnutzer in Kasachstan waren 2010 zwischen 16 und 24 Jahre alt und fast $35 \%$ aller Kasachstaner surften regelmäßig in Internet; in Usbekistan lag die Zahl der jungen Internetnutzer (16 bis 24 Jahre alt) bei $39 \%$, wobei etwa $30 \%$ aller Usbeken im Jahr 2012 über einen Internetzugang verfügten. Auch in Hinblick auf Häufigkeit und Dauer der Internetnutzung stand die Gruppe der jungen Menschen in den oben genannten Ländern an der Spitze. Nicht zuletzt trug dazu die Verbreitung des mobilen 
Internets bei, das vor allem in Kasachstan inzwischen einen wichtigen Zugang ins Internet darstellt.

Darüber hinaus zeichnen sich in den letzten zehn Jahren für alle drei zentralasiatischen Republiken typische Tendenzen in der Internetnutzung ab. Erstens findet man unter den Top-10 der meistbesuchten Websites aller drei Länder die gleichen Adressen: die Webdienste mail.ru und yandex.ru, die außer einer Suchmaschine und einem E-Mail-Dienst zahlreiche Online-Entertainment-Angebote umfassen; die sozialen Netzwerke Vkontakte, Facebook und Odnoklassniki, wobei in Kirgistan und Usbekistan aktuell Facebook und in Kasachstan wie schon seit fünf Jahren Vkontakte die meist genutzten sozialen Netzwerke sind; regionale Websites für Kleinanzeigen wie olx.kz, olx.uz sowie Video- und Musikportale wie youtube.com, mover.uz und namba.kg. Das heißt, das Internet wird in Zentralasien vor allem für Informationssuche, Kommunikation und Unterhaltung genutzt.

Zweitens gehören die in Zentralasien am häufigsten angeklickten Websites hauptsächlich russischen Internetdienstleistern. Dies ist nach Ansicht von Experten darauf zurückzuführen, dass regionale Online-Angebote nicht konkurrenzfähig sind. Die russische Sprache wurde daher zu lingua franca des Internets in Zentralasien. Zwar wurden viele russische Websites wie z. B. yandex.ru und Vkontakte mit der Zeit durch nationalsprachige Versionen erweitert und das nationalsprachliche Web-Angebot verstärkt, bis heute haben aber die meistbesuchten Websites mit den Domain-Endungen $. \mathrm{kz}, \mathrm{kg}$ und .uz vor allem russischsprachige Inhalte.

\section{Internetregulierung auf zentralasiatisch}

Auf den ersten Blick scheint sich die Entwicklung des Internets in Kasachstan, Usbekistan und Kirgistan nicht wesentlich von der in anderen Weltregionen zu unterscheiden. Bei genauerer Betrachtung der Entwicklung bei der staatlichen Regulierung des Internets entsteht aber ein ganz anderer Eindruck.

In allen drei zentralasiatischen Republiken ist das Thema Informations- und Kommunikationstechnologien in der nationalen Gesetzgebung verankert, gleichzeitig wurden auch nationale IT-Konzepte entwickelt, was zu Unklarheiten und Mehrdeutigkeit geführt hat. So stellt z. B. die Änderung des kasachstanischen Mediengesetzes von 2009 alle Websites mit Massenmedien gleich, d. h. Domain-Inhaber wie Internetnutzer, u. a. auch Blogger, übernehmen die volle Haftung für Inhalte bzw. Kommentare, die auf ihrer Seite erscheinen und können nach allgemeinen nationalen Rechtsvorschriften zu Haft- und Geldstrafen verurteilt werden. Laut dieser Gesetzänderung können einheimische wie ausländische Websites vor kasachstanischen Gerichten ange- klagt werden (was z. B. nach deutschem Recht nicht möglich ist). Dies widerspricht allerdings dem staatlichen Konzept "für die Entwicklung eines gemeinsamen Informationsraums im kasachstanischen Segment des Internets "KazNet» für den Zeitraum 2008-2012«, wo die große Bedeutung der globalen Internetentwicklung mehrmals betont und eine internationale Zusammenarbeit im Bereich der Internetregelung gefordert wurde. Am 1. Januar 2016 wurde in Kasachstan außerdem die technische Kontrolle des Internets mittels SSLVerschlüsselung eingeführt. Experten zufolge lassen sich durch diese Neuerung die persönlichen Daten der kasachstanischen Internetnutzer, beispielsweise persönliche Zugangsdaten, abfangen, was das Prinzip des Netzneutralität gefährdet und das Recht auf Anonymität des Internetnutzers verletzt.

In Usbekistan wird das Internet in ganz ähnlicher Art und Weise reguliert und überwacht. Seit 2014 ist ein Gesetz in Kraft, das strafrechtliche Konsequenzen für den Fall androht, dass der Inhaber einer Website gefährliche Inhalte wie Extremismus- und Kriegspropaganda, Aufruf zu einer Revolution in Usbekistan etc. auf seiner Seite zulässt. Was genau unter diese gefährlichen Inhalten fällt und wie die Medien-Expertise durchgeführt werden soll, ist im Gesetz nicht klar formuliert.

Wie in Kasachstan sahen auch viele Blogger in Usbekistan in diesem Gesetz unter anderem einen Versuch, die Meinungsfreiheit im Land einzuschränken. Diese Meinung teilen auch internationale Medienexperten, die Internetzensur in Kasachstan und Usbekistan mit der Blockierung der für die Regierungen »unerwünschten "Websites verbinden. Mittlerweile werden in beiden Staaten immer mehr Websites langfristig blockiert, darunter Webangebote mit unzweifelhaft gefährlichen, radikalen Inhalten, aber auch unabhängige und internationale Online-Nachrichtenwebsites, wie beispielsweise ratel.kz, meduza.io, dailymail.com u. a. in Kasachstan und fergananews.com, ozodlik.org, dw.com u. a. in Usbekistan.

Während Kasachstan und Usbekistan wegen der Kontrolle der Internetnutzung von der internationalen Organisation "Freedom House« im Jahr 2015 als "not free« eingestuft wurden, blieb Kirgistan als einziger Staat Zentralasiens auf dem nächstbesseren Rang "partly free». Zwar muss man auch hier einige kurzfristige Blockierungen von Websites feststellen und die Debatte über Informationssicherheit und Internetkontrolle hat sich ständig intensiviert, aber in Kirgistan werden Websites Massenmedien gesetzlich nicht gleichgestellt und das Verfahren der staatlichen Regulierung des Internets sieht relativ transparent und eindeutig aus. Dennoch heben Experten die Problematik der Selbstzensur im kirgisischen Internet hervor, die sie mit der aktuellen 
Verschärfung des Strafrechtes bei Anstiftung zum ethnischen Hass und Extremismus in Verbindung bringen.

\section{Doppeldeutiger Jugendmedienschutz}

Seit einigen Jahren ist auch speziell das Thema Jugendmedienschutz immer häufiger in der politischen Diskussion der drei Länder zu finden. In den Mittelpunkt werden dabei soziale Medien wie Facebook, Vkontakte u. ä. als Quellen schädlicher Inhalte und Treffpunkt gefährlicher Online-Communities gestellt. Besonders akut wird gegenwärtig die Verbreitung radikalen politischen und religiösen Gedankenguts über soziale Netzwerke debattiert, darunter vor allem IS-Propaganda und -Rekrutierung im Netz, die sich besonders an junge, sozial benachteiligte Menschen aus der Region wendet. In diesem Zusammenhang wird von zentralasiatischen Politikern die Verstärkung der staatlichen Kontrolle insbesondere der sozialen Medien nicht nur auf nationaler, sondern auch auf supranationaler Ebene diskutiert. Eine aktive Zusammenarbeit für Terrorismusbekämpfung im Internet findet z. B. in der Shanghai Organisation für Zusammenarbeit (SCO) statt. Diese regionale Zusammenarbeit lässt zudem die zentralasiatischen Länder die Erfahrung Russlands im Bereich der Internetzensur übernehmen. So trat z. B. im Jahr 2012 das Gesetz "für den Schutz der Kinder vor Informationen, die sich negativ auf ihre physische und geistige Entwicklung auswirken können « in Russland in Kraft. Sein Ziel war angeblich, den Zugang von Minderjährigen zu gewalttätigen PC-Spielen, Pornographie und anderen schädlichen Inhalten unter anderem aus dem Internet einzuschränken. OSZE-Experten bewerten dieses Gesetz jedoch als Versuch, die Freiheit der Informationsverbreitung im Land zu limitieren. Kurze Zeit später kamen mit diesem russischen fast identische Gesetze in die Parlamente Kasachstans, Usbekistans und Kirgistans. In Usbekistan wurde das Gesetz Ende 2014 verabschiedet, was von internationalen Organisationen scharf kritisiert wurde. In Kasachstan und Kirgistan befanden sich die Gesetzentwürfe zwar in der parlamentarischen Beratung, wurden aber bis jetzt noch nicht verabschiedet.

In allen drei Ländern werden außerdem OnlineInhalte in Bezug auf Extremismus regelmäßig von den jeweiligen Informationsministerien überwacht und ggfs. blockiert. Ob diese Blockierungen immer gerechtfertigt sind, ist eine umstrittene Frage. Seit 2010 wurde z. B. in Kasachstan der Bloggingdienst livejournal.com wegen "terroristischer und extremistischer Propaganda w wiederholt blockiert. Die internationale Organisation »Reporter ohne Grenzen « behauptete hingegen, dass diese Sperrung in erster Linie den Zugang zum Blog des früheren Schwiegersohnes des Präsidenten, Rachat Alijew, mit kompromittierenden Fakten über Nursultan Nasarbajew und sein engeres Umfeld einschränken sollte. Die postulierte Gefahr durch Extremismus-Propaganda im Netz wird also gerne als Legitimation für Internetzensur ausgenutzt. Da der in der Gesetzgebung verwendete Begriff "terroristische und extremistische Propaganda" unklar definiert ist, kann er je nach Kontext unterschiedlich ausgelegt wird, was Internetzensur begünstigt.

Des Weiteren wird in der öffentlichen Diskussion Kasachstans und Usbekistans den sozialen Medien der moralische Verfall der Jugend vorgeworfen. Genau wie in Russland werden das Internet und insbesondere die sozialen Netzwerke als Bedrohung traditioneller Werte betrachtet. Die Vielfalt der Online-Inhalte und die Möglichkeit mit Menschen aus der ganzen Welt in Kontakt zu treten, werden besonders von der usbekischen Regierung skeptisch beurteilt. Usbekistan versucht daher eine Art Importsubstitution durchzuführen, d. h. die ausländischen sozialen Medien durch ähnliche einheimische Projekte zu ersetzen und die Online-Kommunikation auf diesem Wege zu kontrollieren. Bislang sind jedoch Facebook und das russische Odnoklassniki weiterhin die in Usbekistan am meisten genutzten sozialen Netzwerke.

\section{Stärkung der Medienkompetenz. Aber wie und wozu?}

Um einen effektiven Jugendmedienschutz im Internet zu realisieren, genügt es nicht, Internetregulierungen zu beschließen bzw. die Umsetzung rechtlicher Rahmenbedingungen zu fördern. Die europäische Erfahrung zeigt deutlich, dass Medienkompetenz eine ebenso bedeutende Rolle spielt. Junge Menschen müssen lernen, Online-Inhalte kritisch zu beurteilen und einzuordnen sowie ihr eigenes Handeln im Netz reflexiv zu betrachten.

In Zentralasien wird der hohe Stellenwert der Medienkompetenz von Kindern und Heranwachsenden seitens der Regierungen und NGOs regelmäßig betont. Die grundlegenden Bestandteile der Medienkompetenz werden in Kasachstan beispielsweise im "nationalen Plan zur Entwicklung der funktionalen Kompetenz der Schüler für die Jahre 2012-2016« mehrmals erwähnt. Dennoch sind zum gegenwärtigen Zeitpunkt noch keine spürbaren Veränderungen in der Praxis festzustellen, was einen formalen Charakter dieses Planes vermuten lässt. Der Plan kündigt u. a. auch die Förderung der technischen Ausstattung von Schulen an, um die Erarbeitung fachlicher Inhalte mittels digitaler Medien zu ermöglichen und zugleich die Medienkompetenz zu stärken. Nichtsdestotrotz verfügen zum gegenwärtigen Zeitpunkt etwa $25 \%$ aller Schulen nicht über einen Breitband-Internetzugang. Auf dem Land beträgt dieser Anteil sogar fast die Hälfte aller Schulen (47,7\%).

In Usbekistan werden die Verwendung von Computertechnologien im Bildungsprozess und der kompe- 
tente Umgang mit Online-Ressourcen ebenfalls intensiv diskutiert. Etwa 14\% der Schulen Usbekistans haben allerdings noch keine modernen PC-Räume. Immerhin präsentierte das Ministerium für Hochschul- und Fachbildung der Republik Usbekistan im März dieses Jahres ein Lehrbuch "Schutz gegen Internet-Gefahren", das nun ein Teil eines obligatorischen Hochschulmoduls werden soll. Im Vordergrund des Lehrbuchs steht allerdings die Gefahr des religiösen Extremismus, was selbstverständlich wichtig ist. Auf Medienkompetenz im breiten Sinne wird aber leider nur oberflächlich eingegangen.

Die Relevanz der Medienkompetenz von Heranwachsenden steht auch in Kirgistan seit einigen Jahren immer häufiger auf der Tagesordnung. Seit 2008 wird mit dem Programm »Ein Kind - ein PC« angestrebt, die Schulen des Landes mit der neuen Technik auszustatten. Aktuell haben jedoch nur 25\% aller kirgisischen Lehranstalten arbeitsfähige PC-Räume. Die Situation soll sich aber demnächst mit dem neuen Programm des Bildungsministeriums »Intelligente Schule« ändern. Das ambitionierte Projekt wird sich nicht nur mit der technischen Ausstattung der Schulen beschäftigen, es sollen auch Medienkompetenz und Computerkenntnisse von Lehrern und Schülern gestärkt werden. Die kirgisische Erfahrung der letzten Jahre lehrt allerdings, dass solche Programme die Medienkompetenz, wenn überhaupt, nur sehr langsam verändern. Trotz aller Programme ist bislang weder Lehrern noch Schülern die Bedeutung der Medienkompetenz wirklich bewusst.

Um diese Situation zu ändern, organisieren NGOs in den zentralasiatischen Staaten praxisorientierte Veranstaltungen für die Stärkung der Medienkompetenz junger Menschen. In Kasachstan und Kirgistan werden regelmäßig Konferenzen und Seminarreihen zu diesem Thema von Internews Network, School of Peacemaking and Media Technology, der OSZE-Akademie in Zusammenarbeit mit der DW-Akademie u. a. durchgeführt. Ein gutes Beispiel ist auch die journalistische UNESCOSommerschule für Studenten, bei der letztes Jahr das Thema Medienkompetenz im Zentrum stand. In diesem Jahr wurde zusätzlich ein sogenannter »UNESCOZug der Medienkompetenz« in Süd-Kasachstan initiiert, der insbesondere kasachischsprachigen Bürgern einen kritischen und reflexiven Umgang unter anderem auch mit Online-Medien vermitteln soll.

\section{Fazit}

Die Entwicklung der Struktur des Internets bzw. seines Zugangs in Kasachstan, Usbekistan und Kirgistan lässt sich insgesamt deutlich positiv einschätzen. Im Laufe der letzten fünf Jahre wurde in allen drei Ländern eine leistungsfähige digitale Infrastruktur eingerichtet, wobei auch die Zahl der Internetnutzer wie die der nationalen Websites rasant stieg. Kennzeichnend für die aktuelle Entwicklung in den ausgewählten Ländern ist einerseits die aktive Internetnutzung vor allem von jungen Menschen, andererseits die zunehmende staatliche Kontrolle, die sich in rechtlichen Vorschriften bzw. technischen Einstellungen äußert und Medien-Experten zufolge die Meinungsfreiheit beschränkt.

Angesichts der aktuellen Terrorgefahr und der Versuche des IS unter Heranwachsenden in Zentralasien Kämpfer zu rekrutieren, wird zurzeit immer häufiger das Thema Jugendmedienschutz diskutiert. Besonders kritisch werden von Politikern in diesem Zusammenhang die sozialen Medien betrachtet. Die kasachstanische und usbekische Regierung setzen darüber hinaus einen behaupteten moralischen Verfall von Heranwachsenden mit der Nutzung sozialer Medien in Verbindung. Die Regierungsmaßnahmen in diesem Bereich, sind einerseits notwendig, andererseits erfolgt unter dem Mantel des Jugendmedienschutzes häufig eine Internetzensur.

Die Bedeutung der Medienkompetenz hat man in Zentralasien klar erkannt, sie wird in politischen Diskursen regelmäßig betont und es wurden dazu zahlreiche nationale Programme etabliert - bislang allerdings ohne spürbare Resultate. Einerseits liegt das daran, dass die technische Ausstattung vor allem in den Schulen auf dem Land nach wie vor nicht ausreichend ist und sich daher die Stärkung der Medienkompetenz für die Bildungseinrichtungen noch als etwas Abstraktes darstellt. Man kann darüber hinaus vermuten, dass der kritische und selbstverantwortliche Umgang mit Online-Inhalten seitens der autoritären Regierungen nicht besonders erwünscht ist. Medienkompetenz stellt daher nur eine freundliche Fassade vor Internetzensur dar. Umso positiver sind die Versuche von NGOs zu bewerten, auf die Medienkompetenz in Zentralasien aufmerksam zu machen und jungen Menschen praktische Kenntnisse zu vermitteln.

\section{Über die Autorin:}

Marina Zhir-Lebed promoviert mit einem Stipendium der Konrad-Adenauer-Stiftung an der Otto-Friedrich Universität Bamberg im Bereich Medien- und Internetsoziologie. Im Rahmen Ihres Dissertationsvorhabens beschäftigt sie sich mit der Bedeutung von Online-Inhalten und Medienbildern für die Konstruktion der nationalen Identität bei jungen Menschen aus Kasachstan. 
Lesetipps:

- Freedom House, Freedom on the Net 2015. Privatizing Censorship, Eroding Privacy, October 2015, = <https:// freedomhouse.org/sites/default/files/FOTN\%202015\%20Full\%20Report.pdf>

- Christoforos Papachristou, Kazakhstan: A Poorly Thought-out Surveillance Technique or an Experiment for the West? Cyber Security Intelligence, 16.12.2015, = <https://www.cybersecurityintelligence.com $/ \mathrm{blog} / \mathrm{kazakhstan}$ a-poorly-thought-out-surveillance-technique-or-an-experiment-for-the-west-908.html>

- Inga Sikorskaya, Uzbekistan's Latest Answer to Facebook, IWPR Global Voices Central Asia, 16.6.2016, = < https:// iwpr.net/global-voices/uzbekistans-latest-answer-facebook>

- Central Asian Visions of IT Boom Look Distant, Eurasianet, 14.7.2016, = <http://www.eurasianet.org/node/79226>

\section{STATISTIK}

\section{Internetnutzer in Zentralasien}

Tabelle 1: Anzahl der Internetnutzer in Zentralasien (in Mio., 2000-16)

\begin{tabular}{|l|c|c|c|c|c|c|c|c|c|c|}
\hline & $\mathbf{2 0 0 0}$ & $\mathbf{2 0 0 2}$ & $\mathbf{2 0 0 4}$ & $\mathbf{2 0 0 6}$ & $\mathbf{2 0 0 8}$ & $\mathbf{2 0 1 0}$ & $\mathbf{2 0 1 2}$ & $\mathbf{2 0 1 4}$ & $\mathbf{2 0 1 6}$ \\
\hline Kasachstan & 0,1 & 0,25 & 0,4 & 0,5 & 1,8 & 5,2 & 9 & 9,5 & 10 \\
\hline Kirgistan & 0,05 & 0,15 & 0,3 & 0,6 & 0,8 & 0,9 & 1,1 & 1,7 & 2,1 \\
\hline Usbekistan & 0,12 & 0,27 & 0,7 & 1,7 & 2,4 & 5,5 & 10,4 & 12,8 & 15,5 \\
\hline Tadschikistan & 0,003 & 0,004 & 0,05 & 0,3 & 0,6 & 0,9 & 1,2 & 1,5 & 1,6 \\
\hline Turkmenistan & 0,006 & 0,01 & 0,04 & 0,06 & 0,09 & 0,2 & 0,4 & 0,7 & 0,8 \\
\hline Russland & 2,9 & 6 & 18,5 & 25,8 & 38,4 & 61,6 & 91,4 & 101,2 & 102,3 \\
\hline China & 22,6 & 59 & 94,8 & 138,1 & 299,8 & 460 & 573,3 & 675,1 & 721,4 \\
\hline
\end{tabular}

Anmerkung: 2016=Schätzung für Juli 2016

Quelle: Internetlivestats; <http://www.internetlivestats.com/internet-users-by-country/>

Grafik 1: Anteil der Internetnutzer an der Gesamtbevölkerung (in \%, 2000-16)

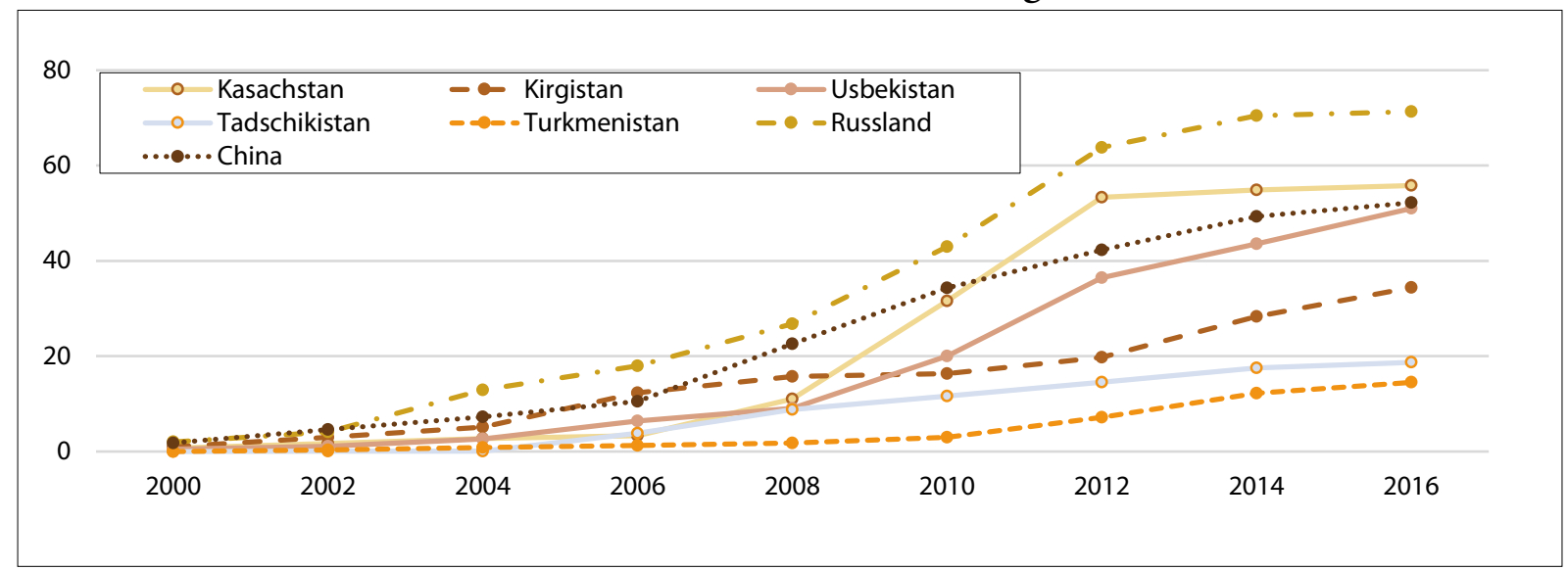

Anmerkung: 2016=Schätzung für Juli 2016

Quelle: Internetlivestats; <http://www.internetlivestats.com/internet-users-by-country/> 
Tabelle 2: Anteil der Internetnutzer an der Gesamtbevölkerung (in \%, 2000-16)

\begin{tabular}{|l|c|c|c|c|c|c|c|c|c|c|}
\hline & $\mathbf{2 0 0 0}$ & $\mathbf{2 0 0 2}$ & $\mathbf{2 0 0 4}$ & $\mathbf{2 0 0 6}$ & $\mathbf{2 0 0 8}$ & $\mathbf{2 0 1 0}$ & $\mathbf{2 0 1 2}$ & $\mathbf{2 0 1 4}$ & $\mathbf{2 0 1 6}$ \\
\hline Kasachstan & 0,7 & 1,7 & 2,7 & 3,3 & 11 & 31,6 & 53,3 & 54,9 & 55,8 \\
\hline Kirgistan & 1 & 3 & 5,1 & 12,3 & 15,7 & 16,3 & 19,8 & 28,3 & 34,4 \\
\hline Usbekistan & 0,5 & 1,1 & 2,6 & 6,4 & 9,1 & 20 & 36,5 & 43,6 & 51 \\
\hline
\end{tabular}

Anmerkung: 2016=Schätzung für Juli 2016

Quelle: Internetlivestats; <http://www.internetlivestats.com/internet-users-by-country/> 


\title{
Halbmondfinsternis. Aufstieg und Niedergang des Islam in Usbekistan seit dem Ende der Sowjetunion
}

\author{
Von Jesko Schmoller, Perm
}

\section{Zusammenfassung}

Angestoßen durch die »Geistliche Verwaltung der Muslime Zentralasiens und Kasachstans« unter Führung des Mufti Muhammad Sodik Muhammad Jusuf und ausgehend von Taschkent erlebte die zentralasiatische Region in den Jahren des Umbruchs der späten 1980er und frühen 1990er eine wundersame Rückkehr der Religion. Diese Entwicklung ist deshalb erstaunlich, weil die Institution des Muftiats im Laufe ihrer Geschichte fast immer eine kontrollierende und regulierende Rolle spielte. Doch zumindest kurzfristig gelang es ihrem Oberhaupt, zwischen 1989 und 1993 an das historische religiöse Erbe anzuknüpfen und dem Islam Zentralasiens zu einer neuen Blüte zu verhelfen. Im Rückblick erscheinen diese wenigen Jahre der religiösen Freiheit als ein historischer Wendepunkt, der das Potential in sich barg, in Usbekistan ein Umfeld zu etablieren, in welchem religiöse Menschen im Einklang mit ihren Überzeugungen leben können. Heute herrscht dagegen ein Klima der Angst vor und Muslime, die sich mit ihren Vorstellungen abseits des staatlich definierten Mainstream bewegen, müssen um den Verlust ihrer Freiheit fürchten.

A

m 11. März 2015 zogen Zehntausende trauernder Menschen durch die Straßen der usbekischen Hauptstadt Taschkent der Kuktscha-Moschee entgegen. Während der Verkehr um die Moschee komplett zusammenbrach, saßen Betende in sich gekehrt am Boden oder weinten still vor sich hin. Sie alle waren gekommen, einen Mann zu ehren, dessen plötzlicher Tod vom obersten Imam Taschkents als "Einsturz des Himmelsgewölbes« bezeichnet wurde.

Der so verabschiedete Muhammad Sodik Muhammad Jusuf war ohne Zweifel die höchste geistliche Autorität im Lande und genoss weit über dessen Grenzen hinaus Respekt. Und doch nahm er eine schwierige Position zwischen der Staatsmacht und der gläubigen Bevölkerung ein, als deren Vertreter er sich betrachtete. Muhammad Sodik kritisierte die Religionspolitik der usbekischen Regierung, die in seinen Augen eine weitere Ausbreitung des Islam verhinderte. Nach etwa sieben Jahren im selbst gewählten Exil in Libyen war er im Jahr 2001 in seine Heimat zurückgekehrt, um den Menschen nahe zu sein, die seinen Rat suchten, wenn er schon die massiven Eingriffe des Staates in ihre Glaubensangelegenheiten nicht unterbinden konnte. Als Folge der mit der Regierung im Vorfeld geführten Verhandlungen musste er sich mit seinen Äußerungen allerdings zurückhalten und konnte Kritik nur in vorsichtigen Dosen äußern. Dieser Drahtseilakt brachte ihm gerade auch von Seiten radikalerer Kräfte Kritik ein. Das gilt etwa für die einflussreiche islamistische Organisation Hizb ut-Tahrir, die an der Schaffung eines islamischen Staates arbeitet, und die zu den von Muhammad Sodik vertretenen Meinungen im Internet wiederholt kritisch
Stellung bezog. Seiner Popularität in der Bevölkerung tat dies kaum Abbruch und viele der von ihm verfassten Texte und Bücher, von denen manche auch ins Russische übersetzt wurden, erfreuen sich bis heute großer Beliebtheit. Abgesehen von diesen Schriften nahm Muhammad Sodik auch direkt Einfluss auf religiöse und politische Amtsträger, die sich als seine Bewunderer und Anhänger regelmäßig bei ihm zu Hause einfanden. Doch seine Tür stand auch jenen offen, die sich mit ihren Fragen zur Bewältigung des Alltags nicht an andere religiöse Autoritäten wenden konnten oder wollten. Frieden unter den Muslimen Usbekistans, der Region und der muslimischen Welt als Ganzes war das Ziel, welches er sein Leben lang verfolgte. Nach seinen Vorstellungen sollten die Gläubigen ihre Differenzen überwinden und sich vereinen. Aufgrund der Vorsicht, die er walten lassen musste, wenn er seine Ansichten kommunizierte, ist es nicht ganz leicht, ihn eindeutig einzuordnen. Besonders am Herzen lag ihm jedoch offensichtlich die Überwindung der Grenzen, die durch nationale Identitäten und die Zugehörigkeit zu den verschiedenen religiösen Rechtsschulen entstanden sind.

Das Wirken Muhammad Sodiks erscheint auf den ersten Blick rätselhaft bis widersprüchlich: Als Mufti der natürlich staatlich kontrollierten "Geistlichen Verwaltung der Muslime Zentralasiens und Kasachstans« (SADUM) führte er in den letzten Jahren der Sowjetunion beinahe eine religiöse Revolution herbei. Diese Entwicklung ist daher so erstaunlich, als SADUM und seine Vorgängerinstitutionen durchgängig Instrumente waren, mit denen der Islam überwacht und reguliert werden sollte. Doch eben in jener Einrichtung arbeitete sich 
ein Mensch an die Spitze, der maßgeblich daran beteiligt war, dem Islam nach Jahrzehnten der Repression zu einer Wiedergeburt zu verhelfen, die alle Hoffnungen der gläubigen Bevölkerung übertraf. Diese Beobachtung legt nahe, sich nicht allein mit der Person Muhammad Sodiks zu beschäftigen, sondern auch mit der Institution, die er repräsentierte. Davon überzeugt, dass sich die Ereignisse und Phänomene der Gegenwart nur begreifen lassen, wenn man die Vergangenheit miteinbezieht, soll ein Blick in die Geschichte des Wechselspiels zwischen Staat und Islam im Zarenreich und in der Sowjetunion geworfen werden. Allein wenn man den Entwicklungsprozess der Geistlichen Verwaltung und ihr institutionelles Erbe berücksichtigt, kann man die Bedeutung der gesellschaftlichen Re-Islamisierung vor und nach der Unabhängigkeit ermessen. Das gleiche gilt für die besondere Rolle Muhammad Sodiks, der, bildlich gesprochen im Zentrum des Getriebes sitzend, zumindest für ein paar wenige Jahre den gesamten Apparat umfunktionierte. Da Taschkent Ausgangspunkt für die Welle religiöser Rückbesinnung war, wird Usbekistan in den folgenden Absätzen besondere Aufmerksamkeit geschenkt.

\section{Belohnen und Überwachen}

Ein systematischer Eingriff des russischen Staates in die religiösen Angelegenheiten seiner muslimischen Bevölkerung begann Ende des 18. Jahrhunderts unter Katharina der Großen. Die aufgeklärte Herrscherin sprach ihren Untertanen das Recht auf die Ausübung ihrer unterschiedlichen Religionen zu und im Jahre 1788 begründete sie eine Institution, die als »Orenburger Mohammedanische Geistliche Verwaltung« bekannt wurde, auch wenn sie ihren Sitz fast durchgängig in Ufa hatte. Das bedeutet, dass sie die Muslime des Reiches mit einer Einrichtung ausstattete, die eine kirchenähnliche Struktur aufwies. Von der Kaiserin selbst als Geschenk verstanden, sollte die muslimische Bevölkerung zukünftig keine untergeordnete Stellung mehr einnehmen, auch wenn für die sie repräsentierende Institution die christliche Kirche Modell stand. Dies bedeutete aber auch einen Versuch der Integration des Islam in das administrative System des Staates. Mit der Geistlichen Verwaltung sollten fortan Ordnung und Disziplin auf die religiöse Praxis Einfluss nehmen. Man wollte die Verbreitung von Ideen, die von außerhalb des Reiches kamen, unterbinden und die Inhalte der religiösen Lehre zumindest regulieren. Mullahs, Imame und andere muslimische Amtsträger brauchten zur Ausübung ihrer Tätigkeit nun ein Zertifikat. Im 19. Jahrhundert wurde es in vielen Moscheen üblich, einen Eid auf den Zaren zu schwören und für die kaiserliche Familie zu beten.

Die Bolschewiki griffen auf die Institutionen der Zarenzeit zurück, um das riesige Gebiet der 1922 begründeten Sowjetunion unter Kontrolle zu halten. Im Jahre 1923 riefen sie nach den Wirren des Bürgerkrieges das Muftiat in Ufa wieder ins Leben, das später in die "Geistliche Verwaltung der Muslime des europäischen Teils der Sowjetunion und Sibiriens" umbenannt wurde. Während des Zweiten Weltkrieges machten die Machthaber Zugeständnisse an die Bevölkerung, um einem Zusammenbruch des Staatsgebildes vorzubeugen. Die muslimische Bevölkerung profitierte von dem neuen politischen Kurs insofern, als dass die staatlichen Repressionen gegenüber islamischen Institutionen und deren Personal nachließen. 1943 wurden weitere Geistliche Verwaltungen, darunter zum ersten Mal auch eine in Zentralasien, eingerichtet. Für die Ausbildung zukünftiger religiöser Amtsträger übernahm diese neue "Geistliche Verwaltung der Muslime Zentralasiens und Kasachstans", die ihren Sitz in Taschkent hatte, schon bald eine tragende Rolle.

Die Sowjetzeit ist nicht allein als Epoche der Kontrolle und Unterdrückung religiöser Kultur zu begreifen. Zum einen gelang es, Aspekte der muslimischen Tradition, wie die Feierlichkeiten des Lebenslaufes, in den Alltag hinüber zu retten. Zum anderen brachten nicht wenige Menschen scheinbar widersprüchliche Positionen miteinander in Einklang und konnten beispielsweise gleichzeitig Mitglied der Kommunistischen Partei sein und ein Beschneidungsfest für den Sohn organisieren. Dennoch ist der Blick in die sowjetische Vergangenheit bei zentralasiatischen Muslimen heute mehrheitlich von negativen Gefühlen geprägt.

\section{Augenblicke der Hoffnung}

SADUM stand mit seinen Aktivitäten von Anfang an unter strenger staatlicher Überwachung. Und trotzdem entwickelte es sich - unter Führung von Muhammad Sodik Muhammad Jusuf - zum Ausgangspunkt einer Bewegung der spirituellen Erneuerung. Widmen wir uns im Folgenden also der Person, die bis zum Untergang der Sowjetunion für die zentralasiatische Region das Amt des Muftis ausübte.

Muhammad Sodik kam am 15. April 1952 in Andischan, im traditionell und religiös geprägten Ferganatal der Usbekischen SSR, zur Welt. Die Familie beruft sich auf Vorfahren, die als Sufi-Scheichs des NakschbandiOrdens besondere Autorität genossen. Der Vater Muhammad Sodiks wurde selbst noch im Sufismus unterwiesen, doch aus Furcht vor Verfolgung hielt er sich von der religiösen Praxis fern und nahm keine Schüler an. Der erste Mufti Zentralasiens erteilte ihm 1950 an der berühmten wieder eröffneten Mir-i Arab-Madrassa in Buchara einen Lehrauftrag. Wenige Jahre später wurde er zum obersten Scheich und Wächter des unweit von Buchara gelegenen Schreins des hoch verehrten Mys- 
tikers Bahauddin Nakschband ernannt. Muhammad Sodik selbst erlernte die Grundlagen des Islam von seinem Vater und besuchte gleichzeitig eine sowjetische Schule. Später nahm er an der Mir-i Arab-Madrassa das Studium auf und setzte es am nach Imam al-Buchari benannten Taschkenter Islamischen Institut fort, wo er 1975 einen Abschluss mit Auszeichnung erwarb. Für jene Zeit äußerst ungewöhnlich reiste er nach Libyen und studierte dort an einer islamischen Hochschule. 1980 begann er für SADUM in der Abteilung für internationale Verbindungen zu arbeiten.

Im Laufe der folgenden Jahre gelang es Muhammad Sodik offensichtlich, nicht nur in Taschkent, sondern ganz Usbekistan und der gesamten Region religiöse Würdenträger durch sein Wissen, seine Fähigkeiten und Persönlichkeit zu beeindrucken. Am 6. Februar 1989 wählte die "Versammlung der Muslime Zentralasiens und Kasachstans « den gerade erst 37jährigen zum Mufti. Schaut man sich Videomaterial des Ereignisses an, scheinen die Freude und Begeisterung der Menge beinahe greifbar. Wieder und wieder hallt der Ruf "Gott ist groß!« durch den Saal und verleiht einer neuen Aufbruchsstimmung Ausdruck. Im selben Jahr wurde der junge Mufti außerdem zum Abgeordneten des Obersten Sowjet der UdSSR, dem höchsten gesetzgebenden Organ des Staates, gewählt. Er nutzte das politische Amt und seine direkte Verbindung zum Generalsekretär der Kommunistischen Partei, Michail Gorbatschow, zur Umsetzung seiner Ziele im Bereich der Religion. Plötzlich erlangte die Bevölkerung religiöse Freiheiten, die für viele absolute Neuerscheinungen darstellten. Zum Beispiel konnten 1990 Tausende Muslime aus Zentralasien zum ersten Mal in ihrem Leben die Pilgerfahrt nach Mekka durchführen. Durch an den heiligen Stätten vorgenommene Restaurationsmaßnahmen gewann auch das Pilgerwesen innerhalb der Region an Dynamik, wurde von Seiten der Geistlichen Verwaltung allerdings vorsichtig reguliert. Um Abweichungen von der vorgeschriebenen religiösen Praxis zu unterbinden, teilte Muhammad Sodik jedem Schrein einen Imam zu, der dafür zu sorgen hatte, dass sich die Besucher vor Ort korrekt verhielten. Sie sollten von Opfergaben absehen und sich mit ihren Bitten um Schutz, Heilung und Hilfe nicht an einen Heiligen, sondern direkt an Gott wenden. Die vielleicht bemerkenswerteste Leistung des neuen Oberhaupts von SADUM war die Eröffnung von mehreren Tausend Moscheen in den wenigen Jahren seiner Amtszeit.

\section{Der Anfang vom Ende}

Das Ende der Sowjetunion im Jahre 1991 führte auch zur Auflösung der "Geistlichen Verwaltung der Muslime Zentralasiens und Kasachstans«. Der usbekische
Zweig von SADUM wurde umbenannt in "Verwaltung der Muslime Usbekistans", wobei Muhammad Sodik an ihrer Spitze blieb. Doch die Zeiten und mit ihnen das Verhältnis des Staates zur Religion änderten sich schnell. Schon bald wurde der Islam von Beratern des Präsidenten als potentielle Gefahrenquelle eingestuft. 1993 begannen die Vollzugsorgane des Staates damit, religiöses Personal unter Druck zu setzen und man überzeugte den Mufti davon, zur Wahrung seines Gesichts das Amt auf eigenen Wunsch niederzulegen. Nach einem Sprengstoffanschlag auf sein Wohnhaus entschied sich Muhammad Sodik für das selbstgewählte Exil in Libyen.

Für viele gläubige Usbeken setzen nun wenig erfreuliche Umstände ein. Die politisch motivierten Verhaftungen von mehreren Tausend Menschen durch die usbekische Regierung seit den 1990er Jahren ist allgemein bekannt. Weniger bekannt ist, dass die meisten Verhaftungen und Urteile unabhängig denkende Muslime betrafen. Wegen angeblich verfassungswidriger Aktivitäten, der Mitgliedschaft in verbotenen religiösen und extremistischen Gruppen oder dem Besitz von verbotener Literatur wurden viele von ihnen zu langjährigen Gefängnisaufenthalten verurteilt. In den meisten Fällen bestand ihre »Schuld« darin, auf friedliche Weise ihre religiösen Überzeugungen leben zu wollen. Außer Muhammad Sodik hat die Regierung seit Mitte der 1990er Jahre praktisch jeden muslimischen Denker, der von ihrem vorgegebenen Kurs abgewichen ist, entweder verhaftet oder ins Exil gezwungen. Islamismus diente immer wieder auch als Grund für die Verhaftung von Kritikern des Systems, die keinen Bezug zur Religion hatten. Aus Sicht der Vertreter des Staates unbedingt zu vermeiden sind Positionen, die in ihren Augen als radikal gelten, weil die Religion hier einen gewichtigen Anteil des Alltags einnimmt. Ein alter Mensch mag fünf Mal am Tag beten, aber wenn sich ein junger Mensch für diesen Lebensstil entscheidet, erweckt dies bei Beobachtern bereits Misstrauen. Nun verwehrte man bärtigen Fußballfans den Zugang zum Stadion und forderte Studenten dazu auf, ihre Bärte abzurasieren. Frauen mit Kopftuch wurden auf Polizeistationen verhört und zur Abteilung für Terrorismusbekämpfung gebracht, wenn sie sich weigerten, zukünftig auf das Kopftuch zu verzichten. Die »Verwaltung der Muslime Usbekistans« ist derweil Sprachrohr und ausführendes Organ des Staates geworden.

\section{Rückschau}

In Anbetracht der beschriebenen harschen Unterdrückung des Islam, des heutzutage konfliktreichen Verhältnisses des usbekischen Staates gegenüber der Religion und seiner Bemühungen, ihm genehme Aspekte des Glaubens zu betonen, andere jedoch zu ignorie- 
ren, kann man sich die von Muhammad Sodik mitgetragene Bewegung der religiösen Erneuerung und ihre emotionale Resonanz in der Bevölkerung kaum noch vorstellen. Es scheint, dass damals eine Vielzahl von Faktoren zusammengewirkt und so eine Renaissance des Islam herbeigeführt haben. Zum einen nahmen die Geistlichen Verwaltungen grundsätzlich eine Mittelposition zwischen dem Staat und der Bevölkerung ein und Angestellte, denen es tatsächlich um die Bewahrung des Glaubens ging, hatten gewisse - wenn auch geringe - Möglichkeiten der Einflussnahme. Als nächstes spielte Muhammad Sodik Muhammad Jusuf ohne Zweifel eine herausragende Rolle und verstand es meisterhaft, zur Herbeiführung eines gesellschaftlichen Wandels den richtigen Weg einzuschlagen und über längere Zeit hinweg seine Möglichkeiten auszuschöpfen, ohne klare Grenzen zu überschreiten. Schließ- lich handelte es sich bei den späten 1980er und frühen 1990er Jahren um eine Zeit des radikalen Umbruchs, in denen der Staat nur noch geringe Kontrolle ausübte und das bislang Undenkbare auf einmal in greifbare Nähe rückte. Was genau hinter vorgezogenen Vorhängen geschah, lässt sich bei einem Staat mit undurchsichtigen politischen Strukturen wie Usbekistan nur schwer feststellen. Vermutlich war Muhammad Sodik schlicht zur rechten Zeit am rechten Ort und konnte andere Personen in Machtpositionen, die lange auf eine Rückkehr des Islam gewartet hatten, davon überzeugen, ihm als Anführer einer solchen Bewegung alle Tore zu öffnen. Mit seinem Tod ist diese Stimme nun endgültig verstummt und die Vision eines Heimatlandes, in dem jeder entsprechend der für ihn gültigen religiösen Vorschriften leben kann, erscheint wie ein ferner Traum.

\section{Über den Autor:}

Jesko Schmoller ist wissenschaftlicher Mitarbeiter am »Centre for Comparative History and Political Studies«, einer an der Staatlichen Universität Perm angesiedelten Zweigstelle der Europäischen Universität in St. Petersburg. Er promovierte 2012 am Zentralasien-Seminar der Humboldt-Universität zu Berlin zu den Lebenszielen junger Usbeken und ihrer Karrierewege im Staatsdienst. Im Rahmen eines neuen Forschungsprojekts beschäftigt er sich mit dem traditionellen Islam in der Uralregion.

\section{Lesetipps:}

- $\quad$ BBC Uzbek, "Muftiyning Saylanishi« (Die Wahl des Mufti); der Film zeigt die Wahl Muhammad Sodiks zum Mufti am 6.2.1989, = <https://www.youtube.com/embed/-Q3kjuoYVh4>

- Yaacov Ro'i, Alon Wainer, Uzbekness and Islam. A Survey-based Analysis of Identity in Uzbekistan, Central Asian Affairs, 3(2016), pp. 142-162, herunterzuladen von <http://ceriainitiative.org/?p=2773>

- Sebastien Peyrouse, Does Islam Challenge the Legitimacy of Uzbekistan's Government?, Russia in Global Affairs, 20.4.2016, = <http://eng.globalaffairs.ru/PONARS-Eurasia/Does-Islam-Challenge-the-Legitimacy-of-Uzbeki stans-Government-18118>

- Bruce Pannier, An Unbelievable Turn In Uzbekistan’s Campaign Against Suspect Islamic Groups, Qishloq Ovozi, 21.6.2016, = <http://www.rferl.org/content/qishloq-ovozi-uzbekistan-naqshbandi-arrests-islamic-groups/27872279. html> 


\section{Die »einflussreichste Frau der Welt« zu Besuch in Kirgistan}

Am 13./14. Juli 2016 hat Bundeskanzlerin Angela Merkel als erste deutsche Regierungschefin Kirgistan besucht. Auf dem Weg zum 11. ASEM-Gipfel (Asia-Europe Meeting) in der Mongolei machte sie für knapp 24 Stunden Halt in Bischkek, wo sie noch am späten Abend von Präsident Almasbek Atambajew auf dem Flughafen mit militärischen Ehren empfangen wurde. Am nächsten Tag fanden Gespräche mit Parlamentariern, Vertretern nationaler Minderheiten, geistlichen Würdenträgern und natürlich mit dem Präsidenten statt. Dabei soll auch über schwierigere Themen, wie die negativen Auswirkungen der EU-Russland-Sanktionen auf Kirgistan, den seit 2010 aufgrund eines international umstrittenen Urteils im Gefängnis sitzenden usbekischen Menschenrechtler Asimschan Askarow (dessen Fall in Reaktion auf eine Forderung des UN-Menschenrechtsrates unmittelbar vor Ankunft der Kanzlerin vom Obersten Gericht verhandelt wurde) oder den Umgang mit Minderheiten gesprochen worden sein. Da keine Dokumente zur Unterzeichnung anstanden, besteht das Ergebnis des Aufenthaltes in Worten der Unterstützung. Auf der gemeinsamen Pressekonferenz mit Atambajew kündigte Merkel an, Kirgistan weiterhin in seiner demokratischen und wirtschaftlichen Entwicklung wie auch beim Kampf gegen den islamischen Radikalismus unterstützen zu wollen. Konkreter wurde Hilfe bei der Annäherung an die EU und bei der Ausbildung von muslimischen Geistlichen genannt.

Die Perspektive der Medien auf den Besuch der Bundeskanzlerin unterscheidet sich zwischen Deutschland und Kirgistan (natürlich) stark. Deutsche Journalisten berichteten, wenn ihnen der Besuch überhaupt mehr als eine Randnotiz wert war, von einem »Besuch fernab der Weltpolitik« (FAZ) oder einer »abseitigen Reise» (Zeit online), die einen »eigenwilligen außenpolitischen Akzent« (Spiegel online) setzte. Außerdem wurde die Kürze und Beiläufigkeit des Aufenthaltes mit Worten wie "Zwischenstopp» (DW) oder »Stippvisite« (FAZ) betont. Für Kirgistan war Merkels Besuch dagegen ein großer Tag mit einer entsprechenden Resonanz in den Medien, sowohl quantitativ als auch qualitativ: ein »historisches Ereignis«!

Deutschland hat Kirgistan schon seit seiner Unabhängigkeit besonderes Interesse signalisiert. Lange Zeit war es der einzige EU-Staat mit einer Botschaft in Bischkek, 1998 besuchte Bundespräsident Roman Herzog als erstes westliches Staatsoberhaupt das Land, dem auch mehrere Außenminister, zuletzt Frank-Walter Steinmeier im April 2016, einen Besuch abstatteten. Insgesamt sollen seit 1993 fast 400 Mio. Euro Wirtschafts- und Entwicklungshilfe geflossen sein. Dennoch rätselten sowohl deutsche wie auch - und noch viel mehr - kirgisische Journalisten über Motive und Ziele von Merkels Visite in einem kleinen, weit entfernten, ökonomisch für Deutschland völlig unbedeutenden Land, in dem auch nur noch ca. 8.000 Deutschstämmige (von ehemals ca. 100.000) leben. In Anlehnung an die Formulierung des Kanzleramtes, Merkel wolle ein Signal setzen, dass Deutschland Kirgistans Bemühungen um Demokratie anerkennt, schrieben deutsche Medien von einem »Tribut an die Demokratie« (Reuters), einer »Belohnung« (FAZ) oder einer »Ermunterung" (Spiegel online), die »politisch kostbar« für Kirgistan (ZDF heute) sei. In kirgisischen Medien wurden diverse Spezialisten zitiert, die Merkels Besuch mit der wachsenden Gefahr einer Islamisierung auch Westeuropas begründeten, dem Versuch, sich über Kirgistan des SCO anzunähern oder gar einer besonderen Aura des Landes. Wie wenig man sich vor Ort vorstellen konnte, dass es wirklich um die Unterstützung des demokratischen Weges ging, und nicht ein deutsches Eigeninteresse hinter dem Besuch steckte, lässt sich daran erkennen, dass die von einer ausländischen Nachrichtenagentur lancierte Behauptung, Merkels eigentliches Ziel sei die Verhandlung über die Einrichtung eines Lagers für Syrienflüchtlinge in Kirgistan, für erhebliche Unruhe sorgte.

Natürlich beschäftigten sich kirgisische Medien anlässlich des Besuchen auch mit der Person Angela Merkel. Das freudige Erstaunen darüber, dass die Bundeskanzlerin Russisch mit Atambajew sprach, war in vielen Medien spürbar. Erstaunen, wenn nicht verdeckte Kritik an kirgisischen Politikern, steckt auch in der Information, dass sie in einem normalen Berliner Mehrfamilienhaus wohnt. (Fotos vom gemeinsamen Spaziergang Merkels und Atambajews im Regen, auf denen zu sehen war, dass die Bundeskanzlerin ihren Regenschirm selber trug, haben eine lebhafte Debatte unter Kirgisen auf Facebook ausgelöst, lassen sich in Kirgistan doch selbst Parlamentarier von Mitarbeitern »beschirmen«.)

Die folgende Auswahl von Artikeln aus der recht bunten kirgisischen Presse soll einen Eindruck von inhaltlichen Schwerpunkten und Bewertungen des Merkel-Besuches geben. 


\title{
Der Besuch Merkels: Warum interessiert sich Deutschland für Kirgistan?
}

\author{
Kloop, 12.7.2016 \\ <http://kloop.kg/blog/2016/07/12/vizit-merkel-pochemu-germaniya-interesuetsya-kyrgyzstanom/>
}

Von Aisirek Almasbekowa

Die deutsche Kanzlerin Angela Merkel trifft am 13. Juli erstmals zu einem offiziellen Besuch in Kirgistan ein. Die einen verbinden dies damit, dass Deutschland die Radikalisierung der kirgisischen Gesellschaft befürchtet, andere mit wirtschaftlichen Interessen.

[...]

\section{Radikalisierung der Region?}

Der Politologe Mars Sarijew glaubt, dass sich mögliche »negative Entwicklungen« in Kirgistan in Hinsicht auf die Radikalisierung der Gesellschaft auf Deutschland auswirken könnten. Er führte die Situation in den Staaten Afrikas, des Mittleren Ostens und Syriens an, die die Ursache für die derzeitige Flüchtlingskrise bilden.

[...]

"Deutschland als Juniorpartner der USA und stellvertretend für die westliche Gemeinschaft fürchtet, dass in der einzigen Republik Zentralasiens, die sich auf mehr oder weniger demokratischem Weg befindet, der islamische Extremismus Fuß fassen könnte. Die Bedrohung, die aus Afghanistan kommt, aber auch die Schläferzellen, die sich innerhalb des Landes gebildet haben, könnten sich radikalisieren, deshalb herrschen bei ihnen sehr große Befürchtungen«, sagte Sarijew in einem Interview mit Kloop.kg.

$[\ldots]$

Aus dem Russischen von Henryk Alff

\section{Wofür nur ist Frau Merkel hergeflogen?}

Delo No., 14.7.2016

<http://www.delo.kg/index.php/health-7/9613-zachem-zhe-priletala-frau-merkel>

\section{Von Wadim Notschowkin}

Der Besuch der deutschen Bundeskanzlerin in Kirgistan hat bereits vor ihrer Ankunft zahlreiche Gerüchte hervorgerufen. Welche haben sich bestätigt, welche nicht?

Die Aufregung, die der Besuch der deutschen Kanzlerin Angela Merkel in Kirgistan auf ihrem Weg in die Mongolei ausgelöst hat, war vollkommen verständlich. Noch nie zuvor war ein Staats- und Regierungschef Deutschlands des mächtigsten Staates der EU - zu einem offiziellen Besuch nach Kirgistan gekommen. Eine Ausnahme bildet der Besuch des Bundespräsidenten im Jahr 1998, doch der Präsident erfüllt in Deutschland eher repräsentative Aufgaben, die reale Macht liegt in den Händen der Kanzler.

[...] Der kirgisische Präsident begrüßte die deutsche Kanzlerin auf Deutsch: „Guten Abend«, »Dobry wetscher!» antwortete ihm Frau Merkel auf Russisch. Und für den von Atambajew überreichten Blumenstrauß bedankte sie sich erneut auf Russisch: "Spasibo bolschoe!« Darin zeigte sich zweifellos ihre Biographie - ihre Kindheit und einen Teil ihres bewussten Lebens verbrachte Merkel bekanntermaßen in der DDR, sie war Mitglied der Pioniere und im deutschen Komsomol (FDJ - Anm. des Übersetzers).

[...]

Doch was hat Frau Merkel interessiert? Erstens, die interreligiöse Situation in Kirgistan, Fragen von Extremismus und Terrorismus. Zweitens, die zwischenethnische Situation. Nach unseren Informationen hat Angela Merkel ihren Gesprächspartnern mitgeteilt, dass sie bei dem bevorstehenden Treffen mit Almasbek Atambajew die Frage nach der proportionalen Vertretung verschiedener Ethnien in den staatlichen Strukturen Kirgistans, darunter von nationalen Minderheiten, aufwerfen werde. 
Eines der Gerüchte, das dem Besuch der Kanzlerin in Kirgistan vorauseilte, verband ihren Besuch mit dem Schicksal des zu lebenslanger Haft verurteilten Bürgerrechtlers Asimschan Askarow. Eine der internationalen Menschenrechtsorganisationen - das Komitee zum Schutz von Journalisten (CPJ) - hatte Merkel vor ihrer Abreise dazu aufgerufen, ihren Besuch dafür zu nutzen, um »die Aufmerksamkeit der kirgisischen Führung auf die Notwendigkeit der Freilassung von Asimschan Askarow zu lenken.« »Insbesondere bitten wir Sie, energisch an Präsident Atambajew zu appellieren, sich an die Entscheidung des UN-Menschenrechtsrats zu halten, der die Unschuld Askarows feststellte und dessen sofortige Freilassung forderte«, heißt es in einer Stellungnahme der NGO.

Es blieb unklar, welche Beziehung das Komitee für den Schutz von Journalisten (!) mit dem Bürgerrechtler Askarow hat. Doch seine Person wurde in den dreistündigen Gesprächen Angela Merkels mit Almasbek Atambajew tatsächlich diskutiert. Dies wurde während der gemeinsamen Pressekonferenz des kirgisischen Präsidenten und der deutschen Kanzlerin bestätigt.

[...]

Ein weiteres Gerücht war wahrlich schockierend und brachte die kirgisische Öffentlichkeit in Aufruhr. Die Agentur »Osodagon« mit Sitz in Duschanbe, die sich selbst als »unabhängige regionale Nachrichtenagentur mit Registrierung in Tadschikistan und Kirgistan « bezeichnet, hatte zwei Tage vor dem Besuch der Kanzlerin folgende sensationelle Nachricht verbreitet: Merkel wird in Gesprächen mit Atambajew die Frage nach der Einrichtung eines Auffanglagers für syrische Flüchtlinge in Kirgistan aufwerfen!

[...]

Im Übrigen hat das kirgisische Außenministerium nicht gezögert mitzuteilen, dass in der bestätigten Tagesordnung der bilateralen Gespräche die Flüchtlingsfrage gar nicht auftaucht. Und tatsächlich fanden im Lauf von Merkels Besuch keinerlei syrische Flüchtlinge Erwähnung. So blieb unklar, was das sollte? Ein Durchsickern von Inhalten absolut geheimer Absprachen Berlins und Bischkeks? Oder ein ganz normaler provokativer Einwurf von Information (genauer gesagt Desinformation)? Nur für wen und wozu war dies notwendig?

Im Laufe des Treffens von Almasbek Atambajew und Angela Merkel wurden keinerlei Dokumente unterschrieben. Warum ist die deutsche Bundeskanzlerin dann also hergekommen?

Die Führer beider Staaten diskutierten, wie mitgeteilt wurde, ein "sehr breites Themenspektrum - von Wirtschaftsfragen und Politik bis hin zum kulturell-humanitären Bereich." Wenn man die allgemeinen Phrasen zur Ausweitung der Zusammenarbeit einmal weglässt, die Atambajew und Merkel im Rahmen der Pressekonferenz miteinander austauschten, bleibt unter dem Strich folgendes. Deutschland wird möglicherweise in der Zukunft die Entwicklung von kleinen und mittelständischen Unternehmen unterstützen. Kirgistan kann bis zu 6.000 Warenkategorien zollfrei in die EU einführen. Doch dazu müssen in Kirgistan moderne Laboratorien eingerichtet werden, die die Qualität dieser Waren bestätigen. Kurz gesagt ist die Situation genau die gleiche wie mit der Eurasischen Wirtschaftsunion (EEU), auf deren Binnenmarkt viele kirgisische Waren wegen des Fehlens solcher Laboratorien nicht gelangen können.

Jetzt steht die Erarbeitung einer sogenannten »Road Map« der Zusammenarbeit, insbesondere konkreter ernsthafter Projekte auf der Tagesordnung. Almasbek Atambajew merkte an, dass sich die kirgisische Seite, die nach seiner Einschätzung »ihre Hausarbeiten nicht gemacht hat«, bis zum Herbst »ein wenig bewegen sollte».

Aus dem Russischen von Henryk Alff

\section{Die deutsche »Eiserne Lady»}

Slowo Kyrgyzstana, 12.7.2016

<http://slovo.kg/?p=72644>

[...]

In Reaktion auf die Bewegung gegen die Islamisierung in der deutschen Gesellschaft erklärte A. Merkel, dass »der Islam ein Teil von Deutschland sei«. Für diese Aussage wurde sie von vielen Politikern scharf kritisiert. Ebenso muss man die überzeugte antisemitische Politik A. Merkels betonen.

Es ist hervorzuheben, dass A. Merkel mit ihrem Mann I. Sauer in einem normalen Mehrfamilienhaus wohnt, da sie auf eine Dienstwohnung verzichtet hat. Ihre Freizeit verbringt sie gern mit Gartenarbeit, sie liest viel und reist gern. 
Ihre Idole sind die Physikerin Marie Curie, der Politiker Ludwig Erhard, der Philosoph Aristoteles und ihr Lieblingsschauspieler ist Robert Redford. In der Musik favorisiert sie Klassik, insbesondere Opern von Richard Wagner.

A. Merkel ist lange vor ihrer Karriere, noch als Studentin, zum Fußballfan geworden. Während der WM 2014 verfolgte sie persönlich das siegreiche Endspiel der deutschen Auswahl.

Die übliche Kleidung der deutschen Regierungschefin ist ein strenges Kostüm. In der Regel sind dies Hosen in Verbindung mit einem Blazer mit drei oder vier Knöpfen. Merkel ist keine Freundin von Schmuck, sie trägt weder Ringe, noch Ketten oder Ohrringe.

Die Geste, die zum "Markenzeichen« Merkels geworden ist, betrifft die Haltung ihrer Hände. Vor den letzten Wahlen hingen Plakate mit den Händen der Kanzlerin in ganz Deutschland.

Auf ihrem Schreibtisch steht ein Portrait der russischen Zarin Katharina II., welche Merkel für eine starke Frau hält.

A. Merkel ist dafür bekannt, in jeder beliebigen Situation die Ruhe und ihre »stille Kraft« zu bewahren. Auf ihrem Tisch steht eine silberne Plakette mit der Aufschrift »In der Ruhe liegt die Kraft.» (Im Original deutsch und russisch, Anm. des Übers.)

Aus dem Russischen von Henryk Alff

\section{Die einflussreichste Frau der Welt besucht Kirgistan}

Wetschernyj Bischkek, 14.7.2016

<http://www.vb.kg/doc/343414_segodnia:_auf_wiedersehen_frau_bannery_s_parandjoy_tekebaev_i_ego_zakon. html>

\section{Von Erkin Suromtschujew}

Nichts wurde mit ihr unterschrieben, doch über alles wurde gesprochen. Das Treffen auf höchster Ebene zwischen der deutschen Kanzlerin und dem Präsidenten unseres Landes mag zwar nicht mit Konkretem ausgefüllt gewesen sein, machte jedoch deutlich: Zwischen beiden Staaten ist alles in Ordnung. Merkel begegnet den Kirgisen und ihrem Staatschef mit Respekt. Irgendwelche zweifelhaften Themen wurden im Rahmen der Gespräche nicht angesprochen.

Präsident Atambajew erklärte, dass hinsichtlich des gesamten Spektrums der besprochenen Themen Einvernehmen besteht. Gesprochen wurde über Terrorismus und Religion. Der Konflikt in der Ukraine fand Erwähnung und die Sanktionen gegen Russland. Und diesbezüglich erklang der wichtigste Gedanke: „Wir haben nicht das Recht, einen großen Krieg in Eurasien zuzulassen.« Atambajew rief die Staaten Europas und Russland auch dazu auf, einen Kompromiss zu finden.

Wie üblich wurde gesagt, dass der Besuch im Geiste vollständigen gegenseitigen Vertrauens und Einvernehmens verlief. Gott sei Dank. Wir hätten sonst begonnen, uns Sorgen zu machen, nachdem wir die »Enten« vom Lager für syrische Flüchtlinge und zur Freilassung des Bürgerrechtlers Askarow gelesen hatten, der des Mordes bezichtigt ist. Kurz und gut, Auf Wiedersehen, Frau... (die letzten drei Worte auf Deutsch, Anm. des Übersetzers) 


\title{
Abduwachap Nurbajew, Parlamentsabgeordneter: „Frau Merkel kommt zu uns, um Ihre Unterstützung für die demokratische Entwicklung unseres Landes auszudrücken«
}

\author{
Fokus.kg, 14.7.2016
}

<http://focus.kg/2016/07/14/abduvahap-nurbaev-zhk-deputaty-demokratiyalyk-zhol-menen-n-g-p-baratkan-kyr gyzstandy-angela-merkel-koldoo-ch-n-kelip-zhatat/>

- Heute beginnt der offizielle Besuch der deutschen Bundeskanzlerin Angela Merkel in Kirgistan. Welche Bedeutung hat dieser Besuch für Kirgistan?

- Meiner Meinung nach kommt Frau Merkel nach Kirgistan, um damit ihre Unterstützung für die demokratische Entwicklung des Landes auszudrücken. Deutschland ist einer der mächtigsten Staaten der Welt. Seine Rolle in der EU ist enorm. Außerdem gehört Frau Merkel zu den einflussreichsten Führern der Welt. Deshalb ist dieser hochrangige Besuch für Kirgistan sehr bedeutend.

$[\ldots]$

- Manche Experten sagen, dass Merkels Besuch für Kirgistan ein historisches Ereignis darstellt. Stimmen Sie dem zu? - Natürlich ist das ein historischer Besuch. Wir haben Wahlen unter Anwendung der biometrischen Daten abgehalten und den Weg zur Demokratie eingeschlagen. Politiker wie Frau Merkel unterstützen diese Entwicklung und wollen uns helfen. Wir müssen diese Anerkennung nutzen.«

Aus dem Kirgisischen von Mahabat Sadyrbek

\section{Der Besuch von Frau Merkel ist Vergangenheit}

Azattyk Ünalgysy, 14.7.2016

<http://www.azattyk.org/a/kyrgyzstan_germany_angela-merkel_atambaev/27856717.html>

$[\ldots]$

Bundeskanzlerin Merkel traf den Vorsitzenden des Parlaments Tschynybaj Tursunbekow und einige Fraktionsvorsitzende, um mit ihnen über die Zukunft der parlamentarischen Demokratie zu sprechen. Sie tauschte sich auch mit den Religionsführern aus. In einem Gespräch mit Mufti Maksat aschy Toktomuschow und Episkop Danil hat sie über Möglichkeiten einer Vorbeugung vor der sich im Land ausbreitenden Radikalisierung gesprochen.

Nach Einschätzung der politischen Beobachterin Erkaiym Mambetalijewa ist es wichtig, dass Frau Merkel in einer Zeit, in der der Terrorismus eine der größten Bedrohungen für Europa darstellt, die Bedeutung der religiösen Sicherheit in Zentralasien, darunter auch Kirgistan, als wichtiges Thema erkennt. "Wie Regierung, Muftiat und zivilgesellschaftliche Institutionen im Bereich der Religion arbeiten, ist für sie (die Europäer, Anm. der Übers.) nicht uninteressant. Weil in den vergangenen Tagen die Terrorismusgefahr aktuell und beunruhigend ist. Damit ist auch die Flüchtlingsproblematik eng verbunden. Deshalb zwingt die religiöse Situation in Zentralasien, darunter in Kirgistan, die deutsche Kanzlerin zum Nachdenken."

Während viele Beobachter den Besuch der deutschen Kanzlerin Angela Merkel, einer der bedeutendsten Führer der Welt, in Kirgistan als großen Pluspunkt bewerten, finden einige andere das Treffen nutzlos. Der ehemalige Abgeordnete Rawschan Dscheenbekow meint, dass Kirgistan, auch wenn es das einzige demokratische Land in der Region ist, wegen seiner russlandfreundlichen Außenpolitik konkrete Hilfe weder von Deutschland noch von der Europäischen Union bekommen wird. „Hätten wir eine Regierung, die demokratische Werte hochhält und konkrete Reformvorschläge vorlegt, hätte Deutschland Kirgistan in großem Maßstab geholfen, so wie sie zum Beispiel der Ukraine, Moldowa und Georgien seit Jahren fortlaufend viel Unterstützung gewähren. Da unsere Regierung sich an dem russischen autoritären Regime orientiert und sich ihm zuneigt, haben sowohl Deutschland als auch die Europäische Union kein Interesse, hier großartig zu helfen." [...] 


\section{Angela Merkel und Kirgistan}

Fabula, 18.7.2016

<http://www.gezitter.org/politic/51914_angela_merkel_i_kyirgyizstan/>

Von Tyntschtyk Altymyschew

[...]

Wie anfangs gesagt, bis jetzt sind aus Deutschland mehr als 261 Mio. US-Dollar überwiesen worden, doch es ist schwierig zu sagen, ob sie sich ausgezahlt haben und der Kirgise die Früchte dieser Hilfe voll und ganz genossen hat. So ist es doch bei uns üblich, aus dem Ausland eingehende Gelder wie ohne Adresse zu behandeln, nebenbei gierig die Hände aufzuhalten und zu stehlen. Und das Schlimmste, so etwas wie Verantwortung und Rechenschaft über die zweckmäßige Ausgabe und Rückgabe von Mitteln gibt es nicht. Als Folge daraus beschränkt sich die Zusammenarbeit zweier Staaten üblicherweise auf »Wir bitten um Geld, sie geben«, und der bilaterale nachhaltige Warenaustausch, Handelsbeziehungen werden nicht vervollkommnet.

[...]

Kurz gesagt, der Besuch Angela Merkels in Kirgistan ist ein positives Ereignis. Wir haben dies alle während des Arbeitsbesuches gesehen. Während des Treffens hat sie sich mit der Frage des religiösen Extremismus befasst und mitgeteilt, dass sie in dieser Hinsicht der kirgisischen Führung mit Hilfe hinsichtlich spezieller Ausbildungseinrichtungen für Imame, zur Sicherstellung ihrer Religionskundigkeit zur Seite stehen will. Zudem hat sie das Thema der Menschenrechte anklingen lassen. Im Vorschlag der UN steht kein Wort zur Freilassung von Asimschan Askarow, er drückt lediglich den aufrichtigen Wunsch aus, dass Offenheit und Transparenz als demokratisches Prinzip geschützt und die Rechte des eines Verbrechens Bezichtigen gewahrt bleiben. Darüber hinaus wurde bekannt, dass sie entgegen vorheriger Prognosen mehrerer provokanter Quellen nicht die Absicht hatte, Gespräche über die Ansiedlung von Flüchtlingen aus dem Nahen Osten zu führen. Es war spürbar, dass sie lediglich gekommen war, um Kirgistan, das als »Inselchen der Demokratie« in Zentralasien bekannt ist, mit eigenen Augen zu sehen und, falls nötig, sich darum zu bemühen, über Kirgistan die geopolitischen Beziehungen mit den Staaten der SCO zu stärken. 


\section{Juni - 22. Juli 2016}

\section{Kasachstan}

\begin{tabular}{|c|c|}
\hline 27.6.2016 & $\begin{array}{l}\text { Premier Karim Massimow empfängt den Präsidenten der EBRD, Sir Suma Chakrabarti, in Astana zu Gesprä- } \\
\text { chen über die bilaterale Zusammenarbeit. }\end{array}$ \\
\hline 28.6.2016 & $\begin{array}{l}\text { Muchtar Kul-Muchammed, stellvertretender Vorsitzender der Präsidentenpartei Nur Otan, trifft am Rande des } \\
\text { Parteitags der russischen Partei Jedinaja Rossija (Einiges Russland) mit dem russischen Premier Dmitrij Medwed- } \\
\text { jew zu Gesprächen zusammen. }\end{array}$ \\
\hline 28.6.2016 & $\begin{array}{l}\text { Ein Gericht im litauischen Vilnius lehnt die Auslieferungsanträge der ukrainischen und kasachstanischen Behör- } \\
\text { den für den Schwager von Ex-BTA Bank-Chef Muchtar Abljasow, Syrym Schalabajew, ab. Schalabajew hatte in } \\
\text { Litauen den Flüchtlingsstatus zuerkannt bekommen. }\end{array}$ \\
\hline 28.6.2016 & $\begin{array}{l}\text { Kasachstan wird mit } 138 \text { von } 193 \text { Stimmen der UN-Vollversammlung als erster zentralasiatischer Staat zum nicht- } \\
\text { ständigen Mitglied im UN-Sicherheitsrat für die Jahre 2017-18 gewählt. }\end{array}$ \\
\hline 28.6.2016 & $\begin{array}{l}\text { Die Welt-Anti-Doping-Agentur (WADA) suspendiert die Akkreditierung des kasachstanischen Doping-Labors } \\
\text { in Almaty für zunächst vier Monate. }\end{array}$ \\
\hline 29.6.2016 & $\begin{array}{l}\text { Nach dem Terroranschlag am Istanbuler Atatürk-Flughafen lässt die kasachstanische Air Astana eine kostenlose } \\
\text { Stornierung von Tickets in die türkische Metropole zu. Eine Maschine der Airline SCAT musste in der Nacht auf } \\
\text { dem Flug nach Istanbul auf den zweiten Flughafen Istanbuls umgeleitet werden. }\end{array}$ \\
\hline 29.6.2016 & $\begin{array}{l}\text { Im Dorf Gulschat (Gebiet Karaganda) nehmen Sicherheitskräfte eine Gruppe von des Islamismus Verdächtigen } \\
\text { fest, die einen Terroranschlag vorbereitet haben sollen. Beim Zugriff sprengt sich einer der Männer in die Luft } \\
\text { und wird dabei getötet. }\end{array}$ \\
\hline 29.6.2016 & $\begin{array}{l}\text { Der türkische Präsident Recep Tayyip Erdogan bedankt } \\
\text { jew ausdrücklich für dessen Bemühungen bei der jüngst }\end{array}$ \\
\hline 30.6 .2016 & $\begin{array}{l}\text { as regierungsnahe turkmenische Nachrichtenportal Nejtralny Turkmenistan meldet, dass Kasachstan Mitglied } \\
\text { es Transportkorridors Central Asia-Middle East (Usbekistan-Turkmenistan-Iran-Oman) geworden ist. }\end{array}$ \\
\hline 30.6 .2016 & $\begin{array}{l}\text { Tengrinews meldet die Festnahme eines Kirgise } \\
\text { mehreren Jahren mit internationalem Haftbefehl }\end{array}$ \\
\hline 1.7.2016 & $\begin{array}{l}\text { Tengrinews berichtet, dass in den vergangenen beiden Jahren bei der staatlichen Eisenbahngesellschaft Kazakh } \\
\text { Temir Scholy mehr als } 1.500 \text { Stellen gekürzt wurden. }\end{array}$ \\
\hline 1.7.2016 & Ab sofort lässt die RF keine Gütertransporte aus der Ukraine nach Kasachsta \\
\hline 3.7 .2016 & Die ehemalige Gesundheitsministerin Salidat Kairbekowa stirbt nach schwerer Kran \\
\hline 4.7.2016 & $\begin{array}{l}\text { Präsident Nasarbajew gratuliert im Rahmen der bevorstehenden Feierlichkeiten zum Tag der Hauptstadt einer } \\
\text { jungen Familie zur Geburt ihres Kindes, des millionsten Einwohners von Astana. Nach Angaben der Stadtver- } \\
\text { waltung soll die Bevölkerung der Hauptstadt in den vergangenen vier Monaten um erstaunliche } 120.000 \text { Bewoh- } \\
\text { ner gewachsen sein. }\end{array}$ \\
\hline 5.7.2016 & $\begin{array}{l}\text { Präsident Nasarbajew empfängt den Aufsichtsratschef des chinesischen Öl- und Gaskonzerns CNPC, Wang Yilin, } \\
\text { in Astana zu Gesprächen über die bilaterale Zusammenarbeit. }\end{array}$ \\
\hline 5.7.2016 & $\begin{array}{l}\text { Die Partner des Tengiz-Konsortiums, geführt durch den US-amerikanischen Konzern Chevron, geben grünes } \\
\text { Licht für 36,8 Mrd. US-Dollar umfassende Investitionen in die Ausweitung der Ölförderung am Tengiz-Ölffeld. }\end{array}$ \\
\hline 5.7.2016 & $\begin{array}{l}\text { Die französische Nachrichtenagentur AFP meldet, dass ein Gericht in Frankreich erneut einen Antrag der Anwälte } \\
\text { von Ex-BTA Bank-Chef Abljasow auf Haftentlassung ihres Mandanten abgelehnt hat. Die litauische General- } \\
\text { anwaltschaft ficht derweil die Ablehnung zweier Auslieferungsgesuche Kasachstans und der Ukraine durch ein } \\
\text { Gericht in Vilnius gegen Abljasows Schwager, Syrym Schalabajew, an. }\end{array}$ \\
\hline 7.7.2016 & $\begin{array}{l}\text { Im Internet taucht unter dem Titel "The Ablyazov Syndicate« ein in Großbritannien produzierter, englischspra- } \\
\text { chiger Dokumentarfilm auf, der die kriminellen Machenschaften von Ex-BTA Bank-Chef Abljasow beleuchtet. } \\
\text { Regisseur ist der ehemalige RIA Nowosti-Korrespondent Mark Hirst. }\end{array}$ \\
\hline 7.7.2016 & $\begin{array}{l}\text { Der am 23.5. im Fall des oppositionellen Nachrichtenportals Nakanune.kz wegen Verleumdung zu 4,5 Jahren } \\
\text { Haft verurteilte Geschäftsmann Tair Kaldybajew wird erhängt in seiner Zelle aufgefunden. Der internationale } \\
\text { Fonds für Meinungsfreiheit „Adil Sös» (Ehrliches Wort) zweifelt in einer Stellungnahme an Suizid. }\end{array}$ \\
\hline 8.7.2016 & $\begin{array}{l}\text { Die Nachrichtenagentur Bloomberg berichtet, dass die kasachstanische Nationalbank durch erfolgreiche Speku- } \\
\text { lationsgeschäfte mit dem britischen Pfund kurz vor dem Brexit erhebliche Gewinne gemacht hat. }\end{array}$ \\
\hline
\end{tabular}




\begin{tabular}{|c|c|}
\hline 9.7 .2016 & $\begin{array}{l}\text { urch eine Pressemitteilung des Gouverneurs des Gebiets Pawlodar wird bekannt, dass sich die Zahl der Milz- } \\
\text { andverdachtsfälle im Dorf Usynsu auf } 25 \text { erhöht hat, nachdem ein Viehhalter ein krankes Rind ohne veterinär- } \\
\text { edizinische Begutachtung geschlachtet und das Fleisch an ein Restaurant verkauft hatte. }\end{array}$ \\
\hline 11.7.2016 & $\begin{array}{l}\text { Bei einer Pressekonferenz des Komitees für Nationale Sicherheit (KNB) erklärt dessen Sprecher Ruslan Karasew, } \\
\text { dass der im Januar festgenommene Geschäftsmann Tochtar Tuleschow konkret darauf hingearbeitet habe, die } \\
\text { Macht im Staat zu übernehmen. Er soll verbrecherische und extremistische Kräfte finanziert haben, außerdem } \\
\text { wurden bei ihm zahlreiche Waffen sichergestellt. }\end{array}$ \\
\hline 11.7.2016 & $\begin{array}{l}\text { Die UN Economic and Social Commission for Asia and the Pacific (ESCAP) und die kasachstanische Regierung } \\
\text { einigen sich in Bangkok über ein Rahmenabkommen zur nachhaltigen Entwicklung in Zentral- und Nordasien. }\end{array}$ \\
\hline 11.7.2016 & ie Nationalbank senkt den Leitzins um zwei Prozentpunkte auf $13 \%$. \\
\hline 12.7.2016 & $\begin{array}{l}\text { Die Polizei im Gebiet Aktöbe überprüft Informationen der lokalen Bevi } \\
\text { bereits seit Jahren in abgelegenen Dörfern die Ermordung von Menschen }\end{array}$ \\
\hline 12.7.2016 & $\begin{array}{l}\text { Ein Gericht in der Stadt Aktöbe verurteilt } 12 \text { Männer, die sich dem IS in Syrien hatten anschließen wollen, zu } \\
\text { Haftstrafen zwischen sechs und acht Jahren. }\end{array}$ \\
\hline 12.7.2016 & $\begin{array}{l}\text { n Gericht in Almaty setzt die } 18 \text { monatige Haftstrafe der ehemaligen Redakteurin des Nachrichtenportals Naka- } \\
\text { ne.kz, Gusjal Baidalinowa, zur Bewährung aus. }\end{array}$ \\
\hline 13.7 .2016 & $\begin{array}{l}\text { In Astana treffen die Außenminister der Kaspi-Anrainerstaaten zu Gesprächen über den rechtlichen Status des } \\
\text { Kaspischen Meeres zusammen. Außenminister Jerlan Idrissow kündigt eine Konvention für } 2017 \text { an. Der Außen- } \\
\text { minister Turkmenistans, Raschid Meredow, bleibt dem Treffen fern. }\end{array}$ \\
\hline 13.7.2016 & $\begin{array}{l}\text { Der Direktor der russischen Weltraumagentur Roskosmos, Igor Komarow, erklärt, dass sein Land nicht die Absicht } \\
\text { habe, sich vom Weltraumbahnhof Baikonur zurückzuziehen. }\end{array}$ \\
\hline 13.7.2016 & $\begin{array}{l}\text { rgananews.com berichtet, dass der im Dezember } 2012 \text { wegen Erpressung zu } 12 \text { Jahren Gefängnis verurteilte Bür- } \\
\text { rrechtler Wadim Kuramschin unter menschenunwürdigen Bedingungen in Isolationshaft sitzt. Sein Gesund- } \\
\text { itszustand hat sich nach Angaben seiner Frau in den letzten Monaten massiv verschlechtert. }\end{array}$ \\
\hline 14.7.2016 & $\begin{array}{l}\text { emier Massimow trifft zu einem Arbeitsbesuch im überwiegend von Kasachen bewohnten Gebiet Bayan-Ölgiy } \\
\text { Westen der Mongolei ein und stellt humanitäre Unterstützung für von einer Schlammlawine betroffene Bürger } \\
\text { r Stadt Ölgiy in Aussicht. Am 10.7. waren in Ögliy ca. } 100 \text { Häuser zerstört und zwei Menschen getötet worden. }\end{array}$ \\
\hline 15.7.2016 & $\begin{array}{l}\text { ie kasachstanweit seit dem Anschlag von Aktöbe geltende gelbe Terrorwarnstufe wird ab 16.7. um } 30 \text { Tage ver- } \\
\text { ngert, meldet Tengrinews. }\end{array}$ \\
\hline 17.7 .2016 & $\begin{array}{l}\text { wird bekannt, dass bei dem Anschlag in Nizza am 14.7. auch eine Frau aus Pawlodar sowie deren in Nizza } \\
\text { ende Tochter und Enkelin sowie eine in Belgien lebende Kasachstanerin ums Leben gekommen sind. }\end{array}$ \\
\hline 2016 & $\begin{array}{l}\text { Bei dem bewaffneten Überfall eines einzelnen Mannes auf das Gebäude des Bezirkshauptquartiers der Polizei in } \\
\text { Almaty und anschließenden Feuergefechten mit der Polizei bei seiner Flucht werden insgesamt fünf Menschen, } \\
\text { darunter drei Polizisten, getötet und drei zum Teil lebensgefährlich verletzt. Der Attentäter kann festgenommen } \\
\text { werden, ein weiterer Tatverdächtiger wird wieder frei gelassen. In Almaty wird die Terrorwarnstufe zunächst auf } \\
\text { Rot erhöht, am Abend aber wieder auf Gelb gesenkt. Präsident Nasarbajew beruft den nationalen Sicherheitsrat ein. }\end{array}$ \\
\hline 18.7.2016 & $\begin{array}{l}\text { Die UNESCO nimmt den in Kasachstan, Kirgistan und Usbekistan gelegenen westlichen Tien-Schan in die } \\
\text { Liste der Welt-Naturerbes auf. }\end{array}$ \\
\hline 19.7.2016 & $\begin{array}{l}\text { Mehrere baptistische Priester berichten, dass sie für die Abhaltung von Gottesdiensten von der Polizei ohne einen } \\
\text { Gerichtsbeschluss mit einer Strafe belegt wurden. Dies sind die ersten bekannten Fälle dieser Art seit dem Inkraft- } \\
\text { treten eines neuen Religionsgesetzes im Jahr 2012, das die Zahl anerkannter Glaubensrichtungen von } 50 \text { auf } 17 \\
\text { verringert hat. }\end{array}$ \\
\hline 19.7 .2016 & $\begin{array}{l}\text { n Gericht in Petropawlowsk (Gebiet Nordkasachstan) verurteilt einen Mann, der sich dem Kampf des IS in } \\
\text { rien angeschlossen hatte und zurückgekehrt war, zu sieben Jahren Haft. }\end{array}$ \\
\hline 20.7.2016 & $\begin{array}{l}\text { Die Sicherheitskräfte nehmen in Aktöbe drei Männer, die sich am Morgen vor dem terroristischen Angriff auf zwei } \\
\text { Waffengeschäfte und einen Stützpunkt der Nationalgarde vor anderthalb Monaten in der Wohnung der Angrei- } \\
\text { fer aufgehalten haben sollen, wegen möglicher Beihilfe zum Terrorismus fest. }\end{array}$ \\
\hline 20.7 .2016 & $\begin{array}{l}\text { Zwei der bei dem Überfall auf das Bezirkshauptquartier der Polizei getöteten Polizisten werden nach einer öffent- } \\
\text { lichen Trauerfeier mit Hunderten von Teilnehmern beigesetzt. }\end{array}$ \\
\hline 21.7.2016 & $\begin{array}{l}\text { Nach Angaben der Polizei soll der Angreifer auf die Polizeistation in Almaty in den letzten sechs Jahren mindes- } \\
\text { tens vier weitere bewaffnete Raubüberfälle in Schymkent und Kysylorda erübt haben. }\end{array}$ \\
\hline
\end{tabular}


22.7.2016 $\quad$ Das Komitee für Statistik meldet, dass im ersten Halbjahr 2016 in kasachstanischen Raffinerien 13,6\% mehr Kraftstoffe (Benzin, Diesel, Kerosin) produziert wurden als im Vergleichszeitraum des Vorjahres.

\section{Kirgistan}

\begin{tabular}{|c|c|}
\hline 16 & $\begin{array}{l}\text { Premierminister Sooronbaj Dscheenbekow trifft zur Teilnahme am Weltwirtschaftsforum Summer Davos } 2016 \\
\text { im chinesischen Tianjin ein. Am Rande der Veranstaltung sind auch Treffen mit seinem chinesischen Amtskolle- } \\
\text { gen Li Keqiang und dem Präsidenten des Weltwirtschaftsforums, Klaus Schwab, geplant. }\end{array}$ \\
\hline 27.6.2016 & $\begin{array}{l}\text { Kirgistan verstärkt nach zwei Milzbrand-Ausbrüchen mit bisher zwei Toten im Norden und Osten von Kasachstan } \\
\text { seine veterinärmedizinischen Kontrollen an der Grenze zum nördlichen Nachbarn. }\end{array}$ \\
\hline 28.6.2016 & $\begin{array}{l}\text { Nach heftigen Regenfällen am Vortag sind in den Bezirken Toktogul und Aksy des Gebiets Dschalalabad Über- } \\
\text { landstraßen durch Erdrutsche unpassierbar und Ortschaften überschwemmt. }\end{array}$ \\
\hline 28.6.2016 & $\begin{array}{l}\text { Der ehemalige Generalstaatsanwalt, Kylytschbek Arpatschijew, wird wegen Erpressung von Bestechungsgeldern } \\
\text { zu } 14 \text { Jahren Freiheitsentzug verurteilt. Er hatte vom Sohn des Parlamentsabgeordneten Karganbek Samakow } \\
\text { 100.000 US-Dollar für die Schließung einer Strafsache verlangt. }\end{array}$ \\
\hline 29.6 .2016 & Zwischen dem 26.-29.6. wurden in Kirgistan 35 Erdstöße der Stärke 3-7 registriert. \\
\hline 29.6 .2016 & $\begin{array}{l}\text { Präsident Atambajew unterzeichnet die Ernennungsurkunden für die durch die Veränderung der Regierungsstruk- } \\
\text { tur neu zu besetzenden Positionen: Samirbek Aidarow wird Minister für Transport und Straßen, Turdunasir Bek- } \\
\text { bojew Minister für Landwirtschaft, Lebensmittelindustrie und Melioration, Dschenisch Rasakow Vize-Premier, } \\
\text { Duischenbek Silalijew Vorsitzender des Komitees für Industrie, Energie und Ressourcennutzung, Bakyt Schar- } \\
\text { schembijew Vorsitzender des Komitees für Informationstechnologie und Kommunikation. }\end{array}$ \\
\hline 29.6 . & $\begin{array}{l}\text { Ein Gericht in Bischkek verurteilt drei Gefangene, die im Oktober } 2015 \text { aus dem Straflager Nr. } 50 \text { im Gebiet } \\
\text { Tschui geflüchtet und wieder festgesetzt worden waren, zu lebenslangen Freiheitsstrafen; zwei Fluchthelfer erhal- } \\
\text { ten vierjährige Gefängnisstrafen. Am 12.10.2015 waren neun wg. Terrorismus Verurteilte aus dem Lager geflo- } \\
\text { hen und hatten dabei vier Wächter ermordet. Drei Flüchtlinge wurden auf der Flucht erschossen, drei waren nach } \\
\text { ihrer Festnahme an Herzproblemen gestorben. }\end{array}$ \\
\hline 29.6 & $\begin{array}{l}\text { Bei dem Terroranschlag auf dem Flughafen von Istanbul wurde ein 22jähriger kirgisischer St } \\
\text { der gerade für einen Flug nach Bischkek eincheckte, teilt der Pressedienst des Außenministeri }\end{array}$ \\
\hline 29.6.2016 & $\begin{array}{l}\text { Auf dem } 3.180 \text { m hohen Teo-Aschuu-Pass, ca. } 120 \mathrm{~km} \text { südlich von Bischkek, wird ein kirgisisch-schweizerisches } \\
\text { Forschungszentrum für Höhenmedizin feierlich eröffnet. }\end{array}$ \\
\hline 30.6. & $\begin{array}{l}\text { Unmittelbar vor dem Beginn der Sommerpause billigt das Parlament mel } \\
\text { renden sowie ca. } 40 \text { weitere Gesetze. Insgesamt soll sich die Volksvertret } \\
\text { Gesetzesprojekten befasst haben, } 80 \text { davon behandelte sie in den vergan }\end{array}$ \\
\hline 30.6 .2016 & $\begin{array}{l}\text { Türkische Medien melden, dass der Anschlag auf den Flughafen von Istanbul von einem russischen Staatsbürger } \\
\text { tschetschenischer Nationalität, einem Kirgisen und einem Usbeken verübt wurde. }\end{array}$ \\
\hline 30.6 .2016 & $\begin{array}{l}\text { Seit Jahresbeginn sind in Kirgistan } 320 \text { Menschen durch Verkehrsunfälle zu Tode gekommen, teilt die Haupt- } \\
\text { verwaltung der Verkehrspolizei mit. }\end{array}$ \\
\hline 30.6 .2016 & $\begin{array}{l}\text { Präsident Atambajew unterschreibt einen Erlass über die Gründung eines Expertenrates zur Stärkung der natio- } \\
\text { nalen Einheit und Religionspolitik, der unterstützend bei Gesetzesprojekten wirken soll. }\end{array}$ \\
\hline 1.7.2016 & $\begin{array}{l}\text { Die Nachrichtenagentur KirTAG meldet die Befreiung eines kirgisischen Staatsbürgers aus der Sklaverei. Der } \\
\text { Mann gibt an, } 2014 \text { von einer Bekannten für } 100.000 \text { Tenge ( } 290 \text { US-Dollar) an einen Kasachen verkauft wor- } \\
\text { den und seitdem im Dorf Tschilik (Gebiet Almaty) zur Arbeit gezwungen worden zu sein. }\end{array}$ \\
\hline 1.7.2016 & $\begin{array}{l}\text { Der staatliche Grenzdienst dementiert Medienberichte, dass usbekische Grenzer sich ein zwischen beiden Staaten } \\
\text { umstrittenes Landstück von 2,5 ha Fläche im Bezirk Aksy (Gebiet Dschalalabad) angeeignet hätten. Die Lage sei } \\
\text { ruhig, beide Seiten würden miteinander verhandeln. }\end{array}$ \\
\hline 1.7.2016 & $\begin{array}{l}\text { Ab sofort lässt die RF keine Gütertransporte aus der Ukraine nach Kasachstan und Kirgistan mehr über ihr Ter- } \\
\text { ritorium zu. }\end{array}$ \\
\hline 4.7.2016 & $\begin{array}{l}\text { In Anwesenheit von Innenminister Kaschakar Dschunuschalijew nimmt in Dschalalabad eine neu gebildete Poli- } \\
\text { zeieinheit mit } 170 \text { Mitarbeitern den Dienst auf, die sich speziell der Aufrechterhaltung der öffentlichen Ordnung } \\
\text { und der Verkehrssicherheit widmen soll. }\end{array}$ \\
\hline
\end{tabular}




\begin{tabular}{|c|c|}
\hline 4.7.2016 & $\begin{array}{l}\text { Sekretär des Verteidigungsrates, Temir Dschumakadyrow, gibt vor der Presse bekannt, dass alle in der Straf- } \\
\text { ffolgung Beschäftigten ab sofort auf Zeitvertragsbasis angestellt werden; nach Vertragsablauf werde je nach Leis- } \\
\text { ng über eine Verlängerung entschieden. }\end{array}$ \\
\hline 5.7.2016 & $\begin{array}{l}\text { Nach den Worten des türkischen Präsidenten Recep Tayyip Erdogan sind unter den im Zusammenhang mit dem } \\
\text { Anschlag auf den Flughafen von Istanbul am 28.6. mehr als } 30 \text { Festgenommenen auch Staatsbürger Kirgistans } \\
\text { (und Tadschikistans). Von kirgisischer Seite wird dies dementiert. }\end{array}$ \\
\hline 6.7.2016 & $\begin{array}{l}\text { Die sterblichen Überreste eines bei einem Erdrutsch in Sowjet-Saj (Gebiet Dschalalabad) am Vorabend mitgeris- } \\
\text { senen Kirgisen werden im usbekischen Dorf Abadan (Gebiet Namangan) gefunden und übergeben. Starke Regen- } \\
\text { fälle hatten in ganz Kirgistan zu Überschwemmungen und Erdrutschen geführt, im Bezirk Toktogul (Gebiet } \\
\text { Dschalalabad) kamen zwei Autofahrer durch herabfallende Felsbrocken ums Leben, Straßen und Häuser wurden } \\
\text { verschüttet und/oder überschwemmt. }\end{array}$ \\
\hline 6.7 .2016 & $\begin{array}{l}\text { Benminister Erlan Abdyldajew trifft während seines Ungarnbesuches mit seinem Amtskollegen Péter Szijjártó } \\
\text { wie dem stellvertretenden Premier Zsolt Semjén zu Gesprächen zusammen. }\end{array}$ \\
\hline 7.7.2016 & $\begin{array}{l}\text { Der staatliche Dienst für Drogenkontrolle wird abgeschafft, bzw. dem Innenministerium eingegliedert. Nach } \\
\text { Angaben von Temir Dschumakadyrow, dem Sekretär des Nationalen Verteidigungsrates, lag die Aufklärungsrate } \\
\text { des Dienstes } 2015 \text { nur bei } 18 \% \text {, die der zuständigen Abteilung des Innenministeriums bei } 80 \% \text {. }\end{array}$ \\
\hline 7.7.2016 & $\begin{array}{l}\text { Der Weltbank-Vorstand bewilligt eine Programmatic Governance and Competitiveness Development Policy Ope- } \\
\text { ration (DPO) für Kirgistan. Sie umfasst zwei aufeinander folgende Budgetunterstützungsmaßnahmen. Die erste } \\
\text { betrifft einen stark vergünstigten Kredit von 13,2 Mio. US-Dollar und eine Unterstützung von 10,8 Mio. US- } \\
\text { Dollar von der International Development Association. }\end{array}$ \\
\hline 7.7.2016 & $\begin{array}{l}\text { Ein Gericht in Bischkek verlängert die Untersuchungshaft für den ehemaligen Staatssekretär Ernest Karybekow } \\
\text { sowie für Bektur Asanow und Kubanytschbek Kadyrow um zwei Monate; auch der Oppositionspolitiker Nur- } \\
\text { lan Motujew bleibt in Haft. Sie waren im März unter dem Verdacht der Planung eines gewaltsamen Machtwech- } \\
\text { sels verhaftet worden. }\end{array}$ \\
\hline 7.7 .2016 & $\begin{array}{l}\text { Bischkek beginnt eine zweitägige Sitzung des Rates für Tourismus der GUS-Mitgliedsstaaten, der dem } 25 \text {. Jubi- } \\
\text { ım der Organisation gewidmet ist. Der Tourismus zwischen GUS-Staaten ist bislang wenig entwickelt. }\end{array}$ \\
\hline 11.7. & $\begin{array}{l}\text { Vor dem Obersten Gericht beginnt unter erhöhten Sicherheitsvorkehrungen die auf Druck des UN-Menschrechts- } \\
\text { rates zustande gekommene Berufungsverhandlung im Fall des usbekischen Menschenrechtlers Asimschan Aska- } \\
\text { row. Der Saal ist überfüllt mit Journalisten, Menschenrechtlern und Vertretern der US- und deutschen Botschaft, } \\
\text { Askarow selbst ist nicht anwesend. Angehörige von kirgisischen Opfern der Unruhen von Osch } 2010 \text { versuchen } \\
\text { die Rechtsvertreter Askarows tätlich anzugreifen. }\end{array}$ \\
\hline 11.7. & $\begin{array}{l}\text { Die } 2010 \text { aus Kirgistan emigrierten ehemaligen Führer der usbekischen Diaspora, Kadyrschan Batyrow und Cha- } \\
\text { lildschan Chudajberdijew, wenden sich im Vorfeld des Kirgistanbesuches der Bundeskanzlerin mit einem offenen } \\
\text { Brief an Angela Merkel, in dem sie auf die ihrer Ansicht nach ungerechte Behandlung der usbekischen Minder- } \\
\text { heit durch die kirgisische Staatsmacht nach } 2010 \text { hinweisen. }\end{array}$ \\
\hline 11.7 .2016 & $\begin{array}{l}\text { i einem Treffen in Bischkek vereinbaren die Generalstaatsanwälte von Kirgistan und Tadschikistan, Indira Jol- } \\
\text { schbajewa und Jusuf Rachmon, eine verstärkte Zusammenarbeit bei Auslieferungen und gegenseitiger Rechtshilfe. }\end{array}$ \\
\hline 12.7 .2016 & $\begin{array}{l}\text { Nach Angaben der nationalen Komitees für Statistik ist das BIP in der ersten Jahreshälfte } 2016 \text { im Vergleich zum } \\
\text { Vorjahreszeitraum um 2,3\% gesunken, die Industrieproduktion sogar um 19,5\%. Die Verbraucherpreise sanken } \\
\text { um } 1,8 \% \text {. Der Handel mit den anderen EEU-Staaten verringerte sich um 2,2\% auf } 770 \text { Mio. US-Dollar. Der } \\
\text { gesamte Außenhandel ging um } 14 \% \text { zurück (Export -29,3\%, Import -8,2\%). }\end{array}$ \\
\hline 12.7 .2016 & $\begin{array}{l}\text { Das Oberste Gericht überweist den Fall des usbekischen Menschenrechtlers Askarow zur Überprüfung an das } \\
\text { Gebietsgericht von Tschui, Askarow bleibt in Haft. }\end{array}$ \\
\hline 12.7 .2016 & $\begin{array}{l}\text { Der Pressedienst von Kyrgyzaltyn teilt mit, dass am Vortag ein Gericht im kanadischen Ontario die Klagen der } \\
\text { türkischen Sistem Muhendislik Insaat Sanayi ve Ticaret Anonim Sirketi und Entes Industrial Plants Constraction } \\
\text { \& Erection Constracting Co. Inc., der kanadischen Stans Energy Corp. und des lettischen Staatsbürgers Walerij } \\
\text { Belokonja gegen die Regierung Kirgistans abgewiesen hat. In dem Verfahren ging es um die in mehreren interna- } \\
\text { tionalen Schiedsgerichtsverfahren beschlossene Übertragung der dem Staatsunternehmen Kyrgyzaltyn gehören- } \\
\text { den Anteile an der kanadischen Centerra Gold Inc. an die Kläger. }\end{array}$ \\
\hline 13.7.2016 & $\begin{array}{l}\text { ganz Bischkek aufgehängte große Plakate, die sich gegen islamische Kleidung wenden, rufen Unruhe und Pro- } \\
\text { t bei den Bürgern hervor. }\end{array}$ \\
\hline
\end{tabular}




\begin{tabular}{|c|c|}
\hline 14.7 .2016 & $\begin{array}{l}\text { Präsident Atambajew empfängt Bundeskanzlerin Angela Merkel zu Gesprächen über die bilaterale Zusammen- } \\
\text { arbeit und internationale Themen. Merkel trifft auch mit Parlamentariern, religiösen Würdenträgern und Vertre- } \\
\text { tern nationaler Minderheiten zusammen. Atambajew äußert den Wunsch nach einer engeren Zusammenarbeit } \\
\text { mit der EU und einem Ende der Russlandsanktionen. }\end{array}$ \\
\hline 14.7. & $\begin{array}{l}\text { Auf der gemeinsamen Pressekonferenz mit Merkel wendet Atambajew sich gegen internationale Kritik an dem } \\
\text { Urteil des Obersten Gerichtes im Fall Askarow. Der UN-Menschenrechtsrat habe nicht die Freilassung Aska- } \\
\text { rows, sondern eine Überprüfung des Urteils auf mögliche Unrechtmäßigkeiten gefordert, diese finde nun statt. }\end{array}$ \\
\hline 14.7 .2016 & $\begin{array}{l}\text { sofort besteht eine wöchentliche Direktflugverbindung zwischen dem sibirischen Irkutsk und Bischkek mit } \\
\text { ia Traffic Company. }\end{array}$ \\
\hline 14.7.2016 & $\begin{array}{l}\text { Vize-Premier Oleg Pankratov } \\
\text { Organization). Beide Seiten v }\end{array}$ \\
\hline 18.7.2016 & $\begin{array}{l}\text { In Reaktion auf den bewaffneten Angriff auf eine Polizeistation in Almaty verstärkt Kirgistan den Schutz seiner } \\
\text { Grenze zu Kasachstan. }\end{array}$ \\
\hline 18.7. & $\begin{array}{l}\text { Die UNESCO nimmt den in Kirgistan, Kasachstan und Usbekistan gelegenen westlichen Tien-Schan in die } \\
\text { Liste der Welt-Naturerbes auf. }\end{array}$ \\
\hline 19.7.2016 & $\begin{array}{l}\text { asident Atambajew unterzeichnet die Gesetze zum CASA-1000 Projekt, die am 16.7. bereits vom Parlament } \\
\text { ifiziert worden waren. }\end{array}$ \\
\hline 19.7 . & $\begin{array}{l}\text { Nach Angaben von Vize-Premier Muchammetkaly Abulgasijew ist das Defizit im Energiesystem des Landes in } \\
\text { diesem Jahr um 1,5 Mrd. Som (22,4 Mio. US-Dollar) gewachsen, insgesamt liegt es bei } 8 \text { Mrd. Som (119,2 Mio. } \\
\text { US-Dollar) - mit steigender Tendenz. Abulgasijew fordert die Bevölkerung zugleich auf, mit Kohle zu heizen, um } \\
\text { dem Energiemangel zu begegnen und Strom für die Versorgung der Industrie zu haben. }\end{array}$ \\
\hline 19.7 & $\begin{array}{l}\text { Ein Bezirksgericht im Gebiet Naryn verbietet die bereits vor zehn Jahren erschienene bekannte zehnbändige } \\
\text { Ausgabe des Nationalepos Manas in der Fassung von Bubu Marijam Musa kysy "Ajkol Manas« (Der edelmütige } \\
\text { Manas) wegen Erniedrigung des kirgisischen Volkes, Verdrehung historischer Fakten und der Gefahr der Ansta- } \\
\text { chelung zu zwischenethnischen Spannungen. }\end{array}$ \\
\hline 20.7 & $\begin{array}{l}\text { r Vorsitzende der Assoziation der Bergbauunternehmer und Geologen Kirgistans, Orosbek Dujschejew, warnt } \\
\text { einer Veranstaltung über Probleme und Perspektiven des kirgisischen Bergbaus, dass die Lage des für die Wirt- } \\
\text { laft des Landes wichtigsten Industriezweiges kritisch sei und sich tendenziell verschlechtere. }\end{array}$ \\
\hline 20.7 .2 & $\begin{array}{l}\text { Die Parteichefs von Ar-Namys, Butun Kyrgysstan und Aalam, Feliks Kulow, Adachan Madumarow und Dschyl- } \\
\text { dyskan Dscholdoschewa teilten vor der Presse mit, dass ihre Parteien eine Koalition gebildet haben. Sie fordern } \\
\text { Änderungen des Wahlgesetzes, um ehrliche und transparente Wahlen zu ermöglichen. }\end{array}$ \\
\hline 21.7.2016 & $\begin{array}{l}\text { Präsident Atambajew unterzeichnet das Gesetz, mit dem von der EU bereit gestellte 3,15 Mio. Euro zur Sicherung } \\
\text { uranhaltigen Abraumhalden in Majluu-Suu (Gebiet Dschalalabad) abgerufen werden können. }\end{array}$ \\
\hline 21.7.2016 & $\begin{array}{l}\text { Vormittag muss das Gebäude des Obersten Gerichtes wegen einer Bombendrohung geräumt werden, die sich } \\
\text { h einer Durchsuchung als falsch erweist. }\end{array}$ \\
\hline 21.7 .2016 & $\begin{array}{l}\text { Auf einer Sitzung des Rates zur Koordination ausländischer Hilfe bittet Premier Dscheenbekow um Unterstüt- } \\
\text { zung internationaler Finanzinstitute für das kirgisische Programm für nachhaltige Entwicklung bis 2023. Seit } \\
1992 \text { hat Kirgistan nach Dscheenbekows Worten mehr als 8,2 Mrd. US-Dollar in Krediten und Fördergeldern } \\
\text { von internationalen Gebern erhalten. }\end{array}$ \\
\hline 22.7.2016 & $\begin{array}{l}\text { In Tscholpon-Ata (Gebiet Issyk-Kul) beginnt das 3. Wirtschaftsforum Issyk-Kul } 2016 \text { mit Teilnehmern aus Russ- } \\
\text { land, Belarus, Indien und China. }\end{array}$ \\
\hline 22.7.2016 & $\begin{array}{l}\text { Am späten Abend bricht ein Feuer in Historischen Museum von Bischkek aus, } 12 \text { Personen werden verletzt, Expo- } \\
\text { nate sollen nicht zu Schaden gekommen sein. Die Brandursache ist noch unklar. }\end{array}$ \\
\hline
\end{tabular}

\section{Tadschikistan}

\begin{tabular}{|l|l|}
\hline 26.6.2016 & $\begin{array}{l}\text { Auf dem Flughafen des ukrainischen Charkow werden zwei aus Istanbul kommende Tadschiken festgenommen, } \\
\text { die wegen Verbindungen zum IS international gesucht wurden. }\end{array}$ \\
\hline 28.6.2016 & $\begin{array}{l}\text { Bei einer Spezialoperation in Duschanbe wurde der in Russland wegen mehrfachen Mordes, Banditentum und } \\
\text { Raub gesuchte Farruch Asamdschonow verhaftet, meldet RIA Nowosti. }\end{array}$ \\
\hline 28.6.2016 & $\begin{array}{l}\text { Beim Einsturz eines Teiles einer Förderstätte in Schugnob (Gebiet Chatlon) kommen zwei Mitarbeiter des Gold- } \\
\text { förderunternehmens Tilloi Totschik ums Leben. }\end{array}$ \\
\hline
\end{tabular}




\begin{tabular}{|c|c|}
\hline 29.6.2016 & $\begin{array}{l}\text { Durch einen Rechenschaftsbericht des Finanzministeriums wird bekannt, dass die staatliche Energieholding Barki } \\
\text { tojik } 10 \mathrm{Mrd} \text {. Somoni (1,3 Mrd. US-Dollar) Schulden hat. Als Ursache werden Kursverluste und mangelnde Zah- } \\
\text { lungsbereitschaft der Kunden genannt. }\end{array}$ \\
\hline 29.6.2016 & $\begin{array}{l}\text { Kamariddin Afsali, der Führer der verbotenen Partei der Islamischen Wiedergeburt (PIWT) im Gebiet Chatlon, } \\
\text { wurde in Istanbul aus der Untersuchungshaft entlassen, meldet der tadschikische Dienst von RFE/RL. Er war vor } \\
\text { zwei Monaten auf tadschikisches Ersuchen von türkischen Sicherheitskräften verhaftet worden. }\end{array}$ \\
\hline 1.7.2016 & $\begin{array}{l}\text { Mit dem heutigen Tag treten das Verbot der Eheschließung zwischen nahen Verwandten sowie das Gesetz über } \\
\text { eine vor der Hochzeit erforderliche Gesundheitsprüfung in Kraft. }\end{array}$ \\
\hline 1.7.2016 & Löhne, Stipendien und Renten steigen mit dem heutigen Tag um durchschnittlich $20 \%$. \\
\hline 1.7.2016 & $\begin{array}{l}\text { Präsidententochter Osoda Rachmon erlegt per Erlass in ihrer Eigenschaft als Vorsitzende des Exekutivapparates } \\
\text { des Präsidenten den Chefs der Gebiete und Bezirke des Landes, Moschee-Vorstehern sowie Wirtschaftsvertretern } \\
\text { die Pflicht für Spenden für Arme, Alte, Kranke, Waisen etc. anlässlich des Endes des Fastenmonats Ramadan auf. }\end{array}$ \\
\hline 1.7.2016 & $\begin{array}{l}\text { Asia-Plus meldet, dass die italienische Gesellschaft Salini Impregilo S.p.A. bereits am 27.6. die Ausschreibung } \\
\text { für den Bau des Rogun-Wasserkraftwerkes gewonnen hat. Präsident Rachmon empfängt den Chef des Unterneh- } \\
\text { mens, Pietro Salini, zur Unterzeichnung der Verträge. }\end{array}$ \\
\hline 1.7.2016 & $\begin{array}{l}\text { Negmatullo Chikmatullosoda, Minister für wirtschaftliche Entwicklung und Handel, und Kristin Laabs, KfW- } \\
\text { Landesdirektorin für Tadschikistan, unterzeichnen einen Finanzierungsvertrag über } 14 \text { Mio. Euro für ein Mut- } \\
\text { ter-Kind-Gesundheitsprogramm sowie die Notfallversorgung im Gebiet Chatlon. }\end{array}$ \\
\hline 1.7.2016 & $\begin{array}{l}\text { Präsident Rachmon empfängt eine Delegation des Vorstandes der EBRD zu Gesprächen über die weitere } \\
\text { Zusammenarbeit. }\end{array}$ \\
\hline 1.7.2016 & $\begin{array}{l}\text { Außenminister Sirojiddin Aslow trifft im Vorfeld eines Treffens der CSTO-Außenminister am 4.7. zu einer offi- } \\
\text { ziellen Visite in Jerewan ein. }\end{array}$ \\
\hline 1.7.2016 & $\begin{array}{l}\text { Ein Erdbeben der Stärke 5-6 erschüttert am Abend den Bezirk Rascht (Bezirke unter Verwaltung der Repu- } \\
\text { blik) und zerstört zahlreiche öffentliche und private Gebäude. Das Epizentrum liegt ca. } 145 \mathrm{~km} \text { nordöstlich von } \\
\text { Duschanbe nahe Garm (Bezirke unter Verwaltung der Republik). }\end{array}$ \\
\hline 2.7.2016 & $\begin{array}{l}\text { Ismoil Talbakow setzt sich bei der Wahl des neuen Vorsitzenden der Kommunistischen Partei Tadschikistans auf } \\
\text { dem 32. Parteitag gegen den langjährigen Vorsitzenden Schodi Schabdolow durch. }\end{array}$ \\
\hline 4.7.2016 & $\begin{array}{l}\text { Die Asian Development Bank (ADB) stellt auf ihrer Website ihre für die Jahre 2016-2018 in Tadschikistan geplan- } \\
\text { ten Maßnahmen zur Unterstützung eines inklusiven Wirtschaftswachstums und von Strukturreformen in Höhe } \\
\text { von } 241 \text { Mio. US-Dollar vor. }\end{array}$ \\
\hline 4.7.2016 & $\begin{array}{l}\text { An der Grenze zu Afghanistan bei Schuroabad (Gebiet Chatlon) kommt es zu einer Schießerei von Grenzern mit } \\
\text { afghanischen Schmugglern, es werden mehr als } 7 \text { kg Drogen beschlagnahmt. }\end{array}$ \\
\hline 5.7.2016 & $\begin{array}{l}\text { Nach Angaben des türkischen Präsidenten Recep Tayyip Erdogan sind unter den im Zusammenhang mit dem } \\
\text { Anschlag auf den Flughafen von Istanbul am 28.6. mehr als } 30 \text { Festgenommenen auch Staatsbürger Tadschi- } \\
\text { kistans (und Kirgistans). }\end{array}$ \\
\hline 5.7.2016 & $\begin{array}{l}\text { Der im Mai verhaftete Mirsonasar Fosilow, Schwiegersohn des ehemaligen Feldkommandeurs der Vereinigten } \\
\text { Tadschikischen Opposition (UTO) Mullo Abdurachim, wurde frei gelassen, meldet Asia-Plus. Die Gründe für } \\
\text { Verhaftung wie Freilassung sind nicht bekannt. }\end{array}$ \\
\hline 6.7 .2016 & $\begin{array}{l}\text { In Reaktion auf Äußerungen des Vorsitzenden des Komitees für ökonomische Zusammenarbeit der russischen } \\
\text { Duma, Leonid Sluzkij, dass Tadschikistan sich in Vorbereitung auf einen Beitritt in die EEU befinde, erklären } \\
\text { Regierungsvertreter in Duschanbe, dass man sich nicht beeile und das Beispiel Kirgistan genau studiere. }\end{array}$ \\
\hline 7.7.2016 & $\begin{array}{l}\text { Die italienische Salini Impregilo S.p.A. kündigt an, die beiden ersten Aggregate für das Wasserkraftwerk Rogun } \\
\text { bereits } 2018 \text { in Betrieb nehmen zu wollen. }\end{array}$ \\
\hline 7.7.2016 & $\begin{array}{l}\text { Der tadschikische Dienst von RFE/RL meldet, dass sich der wegen Mitgliedschaft in der verbotenen Muslimbrü- } \\
\text { derschaft gesuchte stellvertretende Imam der Hauptmoschee von Chudschand (Gebiet Sogd), Orifdschon Erga- } \\
\text { schew, der Polizei des Gebietes gestellt hat. }\end{array}$ \\
\hline 11.7.2016 & $\begin{array}{l}\text { Der Direktor des Zentrums für Strategische Studien, Chudoberdi Choliknasar, berichtet vor Journalisten von einer } \\
\text { neu geschaffenen Freien Wirtschaftszone an der Grenze zu China am Grenzübergang Kulma (Autonomes Gebiet } \\
\text { Berg-Badachschan, GBAO). Auf chinesischer Seite sei bereits ein großes Terminal betriebsfertig. }\end{array}$ \\
\hline
\end{tabular}




\begin{tabular}{|c|c|}
\hline 11.7 .2016 & $\begin{array}{l}\text { Nach Angaben der Vertretung der IOM in Duschanbe wurden in den vergangenen } 11 \text { Jahren } 679 \text { Bürger Tad- } \\
\text { schikistans Opfer von Menschenhandel, mehrheitlich Frauen und Kinder. Sie wurden in der Türkei, arabischen } \\
\text { Staaten, Kasachstan und Russland zu vorwiegend zu sexuellen Diensten gezwungen. }\end{array}$ \\
\hline 11.7 .2016 & $\begin{array}{l}\text { Nach Angaben der Nationalbank lag die Inflationsrate im Bereich privater Konsum in den ersten sechs Mona- } \\
\text { ten } 2016 \text { bei } 3,1 \% \text {. }\end{array}$ \\
\hline 12.7 .2016 & $\begin{array}{l}\text { Die USA haben den in Guantanamo gefangen gehaltenen Tadschiken Muchammadi Dawlatow an Serbien über- } \\
\text { geben, melden tadschikische Medien. Dawlatow soll } 2002 \text { festgenommen worden sein und sich einer Ausliefe- } \\
\text { rung nach Tadschikistan widersetzt haben. }\end{array}$ \\
\hline 13.7.2016 & $\begin{array}{l}\text { Das Gebietsgericht von Chatlon verurteilt drei Männer wegen Propagierung der Ideen der verbotenen PIWT zu } \\
\text { Freiheitsstrafen von zehn und sieben Jahren. }\end{array}$ \\
\hline 14.7.2016 & $\begin{array}{l}\text { Nach Angaben der Eurasischen Entwicklungsbank hat der Rückgang der Rücküberweisungen von Arbeitsmigran- } \\
\text { ten im ersten Quartal } 2016 \text { um ungefähr ein Drittel gegenüber dem Vergleichszeitraum des Vorjahres zu einem } \\
\text { Rückgang der Realeinkommen in Tadschikistan um 0,2\% geführt. }\end{array}$ \\
\hline 14.7.2016 & $\begin{array}{l}\text { Der tadschikische Grenzschutz erklärt in Reaktion auf Berichte afghanischer Medien, dass bei Kämpfen im Bezirk } \\
\text { Kufob der afghanischen Provinz Badachschan ein tadschikischer Staatsbürger zu Tode gekommen und ein wei- } \\
\text { terer verhaftet worden sei, dass ihm keinerlei entsprechende Erkenntnisse vorlägen. }\end{array}$ \\
\hline 14.7.2016 & $\begin{array}{l}\text { Präsident Rachmon empfängt die amtierende Regionaldirektorin für Zentralasien der Weltbank, Mariam Sher- } \\
\text { man, zu einem Gespräch über Stand und Perspektiven der Zusammenarbeit. }\end{array}$ \\
\hline 15.7.2016 & $\begin{array}{l}\text { Nach Angaben der Agentur für Standardisierung wurden in den ersten sechs Monaten des Jahres } 2016664 \mathrm{t} \text { Waren } \\
\text { iranischer Herkunft konfisziert, die nicht tadschikischen gesetzlichen Vorgaben entsprachen, wie auch } 590 \mathrm{t} \text { tür- } \\
\text { kische Produkte und } 169 \mathrm{t} \text { Lebensmittel aus Russland. }\end{array}$ \\
\hline 15.7.2016 & $\begin{array}{l}\text { räsidententochter Osoda Rachmon, die am 29.5. als Nachrückerin in den Senat gewählt worden war, wird von } \\
\text { en Senatoren zur Vorsitzenden des Hauptkomitees der Institution gewählt. }\end{array}$ \\
\hline 15.7.2016 & $\begin{array}{l}\text { Die Staatsanwaltschaft des Gebiets Sogd meldet die Verhaftung von zwei Mitarbeitern der Strafkolonie } 3 / 3 \text { bei } \\
\text { Chudschand, aus der im Vormonat drei Gefangene geflohen waren. }\end{array}$ \\
\hline 18.7.2016 & $\begin{array}{l}\text { Tadschikische Medien berichten, dass derzeit wiede } \\
\text { Entwurf eines Gebietstauschs diskutiert. }\end{array}$ \\
\hline 19.7.2016 & $\begin{array}{l}\text { er tadschikische Dienst von RFE/RL meldet, dass ein Gericht in Duschanbe Muchammadi Rachn } \\
\text { ihrer der verbotenen Salafiten Tadschikistans, zu einer achtjährigen Freiheitsstrafe verurteilt hat. }\end{array}$ \\
\hline 19.7.2016 & $\begin{array}{l}\text { Ein Militärgericht in Duschanbe verurteilt einen Soldaten einer im Bezirk Rascht stationierten Einheit des Ver- } \\
\text { teidigungsministeriums zu vierzehn Jahren und zwei Offiziere zu je zwei Jahren Freiheitsentzug. Sie werden für } \\
\text { den Tod des Wehrpflichtigen Bachtijor Kurbonmadow im April } 2016 \text { verantwortlich gemacht. }\end{array}$ \\
\hline 20.7.2016 & $\begin{array}{l}\text { Nach Angaben des Pressedienstes der Nationalbank ist der Kurs des Somoni gegenüber dem US-Dollar in den } \\
\text { Wechselstuben seit Jahresbeginn um 10,5\% gefallen. }\end{array}$ \\
\hline 21.7.2016 & $\begin{array}{l}\text { ufgrund eines nach Einschätzung der Behörden das tadschikische Volk verletzenden Artikels in der Ausgabe } \\
\text { m 16.7. wird der Vertrieb der tadschikischen Ausgabe der Komsomolskaja Prawda eingestellt. Der Chefredak- } \\
\text { ur der Moskauer Ausgabe der Tageszeitung bestreitet den verletzenden Charakter des Beitrags. }\end{array}$ \\
\hline 21.7 .2016 & $\begin{array}{l}\text { Nach Angaben von Arbeitsministerin Sumangul Tagojsoda sind in den ersten sechs Monaten } 2016308.676 \text { tad- } \\
\text { schikische Staatsbürger nach Russland ausgereist, d. i. knapp 8\% weniger als im Vergleichszeitraum des Vorjahres. }\end{array}$ \\
\hline 21.7.2016 & $\begin{array}{l}\text { Ein Gericht in Duschanbe verurteilt fünf Männer wegen Zugehörigkeit zur verbotenen islamistischen Gruppie- } \\
\text { rung der Salafiten zu je fünf Jahren Freiheitsentzug. }\end{array}$ \\
\hline 21.7.2016 & $\begin{array}{l}\text { Asia-Plus berichtet, dass die fünf im Gebiet Sogd liegenden religiösen Schulen (Medressen), die seit } 2013 \text { bis zur } \\
\text { Erteilung einer Unterrichtserlaubnis geschlossen worden waren, endgültig den Betrieb einstellen mussten. Damit } \\
\text { gibt es in Tadschikistan nur noch eine Medresse. }\end{array}$ \\
\hline 21.7 .2016 & $\begin{array}{l}\text { Die EBRD gewährt der Kleinkreditorganisation Arwand einen Kredit von } 2 \text { Mio. US-Dollar für die Unterstüt- } \\
\text { zung von kleinen und mittleren Unternehmen. }\end{array}$ \\
\hline 21.7.2016 & $\begin{array}{l}\text { Nach den Worten von Arbeitsministerin Sumangul Tagojsoda kann man wegen der Wirtschaftskrise derzeit nur } \\
\text { weniger als der Hälfte der Arbeitslosen des Landes die ihnen gesetzlich zustehende Arbeitslosenhilfe auszahlen. }\end{array}$ \\
\hline 21.7 .2016 & $\begin{array}{l}\text { Nach Angaben der Grenztruppen wurden in der ersten Jahreshälfte an der Grenze zu Afghanistan } 696 \text { kg Dro- } \\
\text { gen beschlagnahmt, es gab } 15 \text { bewaffnete Grenzzwischenfälle mit sieben Toten. }\end{array}$ \\
\hline
\end{tabular}




\begin{tabular}{|l|l|}
\hline 22.7.2016 & $\begin{array}{l}\text { Innenminister Ramason Rachimsoda teilt vor der Presse mit, dass man Gespräche über eine mögliche Ausliefe- } \\
\text { rung des im Exil lebenden Vorsitzenden der seit September 2015 verbotenen PIWT, Muchiddin Kabiri, mit den } \\
\text { Interpol-Mitgliedsstaaten führe. Nach Recherchen des tadschikischen Dienstes von RFE/RL steht Kabiris Name } \\
\text { aber nicht auf der Interpolliste gesuchter Personen. }\end{array}$ \\
\hline 22.7.2016 & $\begin{array}{l}\text { Die chinesische Firma TWEA erhält die Lizenz zur Förderung von Gold in Wostotschnaja Duoba (Bezirk Aini, } \\
\text { Gebiet Sogd). }\end{array}$ \\
\hline 22.7.2016 & $\begin{array}{l}\text { Die untere Kammer des Parlaments präsentiert der Öffentlichkeit einen von ihr herausgegebenen umfangreichen } \\
\text { Bildband mit Fotos von Präsident Rachmon. }\end{array}$ \\
\hline
\end{tabular}

\section{Turkmenistan}

\begin{tabular}{|c|c|}
\hline 28.6.2016 & $\begin{array}{l}\text { In Reaktion auf einen Bericht des oppositionellen Nachrichtenportals Alternativnye Nowosti Turkmenistana } \\
\text { (ANT) über die Explosion eines Benzinlagers auf dem Gelände der Raffinerie in der Stadt Turkmenbaschi (Gebiet } \\
\text { Balkan), bei der mindestens sieben Menschen getötet worden sein sollen, erklärt die staatliche Nachrichtenagen- } \\
\text { tur TDCh, dass der Vorfall durch eine Feuerschutzübung ausgelöst wurde. Angaben über Opfer werden nicht } \\
\text { gemacht. Oppositionelle Websites wollen einen Zusammenhang mit dem gleichzeitigen Ausfall des mobilen Inter- } \\
\text { nets und anderer Kommunikationsdienste im Gebiet Balkan nicht ausschließen }\end{array}$ \\
\hline 30.6 . & $\begin{array}{l}\text { a luxemburgische Frachtflugunternehmen Cargolux gibt bekannt, dass es die Anzahl seiner Flüge über turk- } \\
\text { enische Flughäfen ab dem 1.7. auf täglich elf erhöhen wird. }\end{array}$ \\
\hline 30.6.2016 & $\begin{array}{l}\text { Das iranische Ölministerium teilt mit, dass Iran und Turkmenistan ein Abkommen über den gegenseitigen } \\
\text { Export von Waren und die Bereitstellung von technischen Dienstleistungen in Höhe von 2,5 Mrd. US-Dollar } \\
\text { unterzeichnet haben. }\end{array}$ \\
\hline 30.6 & $\begin{array}{l}\text { Außenminister Raschid Meredow reist in die nördlichen Provinzen Afghanistans, Farjab, Dzhauskhan und Balch, } \\
\text { wo er u. a. hinter verschlossenen Türen mit den Gouverneuren Gespräche über bilaterale Zusammenarbeit vor } \\
\text { allem im Bereich Sicherheit führt. }\end{array}$ \\
\hline 1.7 .2016 & $\begin{array}{l}\text { r jährliche»Trafficking in Persons«-Bericht des U.S. State Departments führt Turkmenistan (und Usbekistan) als } \\
\text { laten auf, deren Regierungen kaum Anstrengungen gegen den weitverbreiteten Menschenhandel unternehmen. }\end{array}$ \\
\hline 1.7 .2016 & $\begin{array}{l}\text { e Gruppe von Bürgerrechtlern wendet sich mit der Bitte an Präsident Gurbanguly Berdymuchammedow, den } \\
\text { teinem Jahr inhaftierten RFE/RL-Journalisten Saparmurat Nepeskulijew freizulassen. }\end{array}$ \\
\hline 2.7.2016 & $\begin{array}{l}\text { lässlich des Endes des Fastenmonats Ramadan begnadigt Präsident Berdymuchammedow insgesamt } 612 \text { Häft- } \\
\text { ge, darunter } 26 \text { Ausländer. }\end{array}$ \\
\hline 2.7 .2 & $\begin{array}{l}\text { Der Chef der türkischen Calik Holding, Ahmet Calik, informiert Präsident Berdymuchammedow über den } \\
\text { Stand der Bauarbeiten an einem Gaskraftwerk im Gebiet Mary, das Calik zusammen mit dem US-amerikani- } \\
\text { schen Konzern General Electric errichtet, und an einem in Zusammenarbeit mit Mitsubishi gebauten Chemie- } \\
\text { werk im Gebiet Balkan. }\end{array}$ \\
\hline 4.7.2016 & $\begin{array}{l}\text { rgananews.com meldet, dass seit mehreren Tagen das mobile Internet über die einzigen beiden Mobilfunkan- } \\
\text { ter Altyn Asyr und MTS in ganz Turkmenistan außer Funktion gesetzt ist. }\end{array}$ \\
\hline 4.7.2016 & $\begin{array}{l}\text { räsident Berdymuchammedow erörtert in einem Telefonat mit seinem türkischen Amtskollegen Recep Tayyip } \\
\text { rdogan Fragen der regionalen und bilateralen Zusammenarbeit. }\end{array}$ \\
\hline 6.7 .2016 & $\begin{array}{l}\text { ach Informationen der russischen Nachrichtenagentur Interfax erhebt Gazprom vor dem Schiedsgericht der } \\
\text { ockholmer Handelskammer Rückzahlungsforderungen von } 5 \text { Mrd. US-Dollar gegenüber dem Staatskonzern } \\
\text { rkmengaz für in den vergangenen Jahren angeblich zu viel gezahlte Liefergebühren. }\end{array}$ \\
\hline 10.7.2016 & $\begin{array}{l}\text { Erst jetzt wird bekannt, dass der staatliche Industrie- und Unternehmerverband bei einer Sitzung am 8.6. große } \\
\text { und mittlere Unternehmen des Landes dazu aufgefordert haben soll, angesichts der schlechten wirtschaftlichen } \\
\text { Lage jeweils mindestens } 100.000 \text { US-Dollar an den Verband zu überweisen. }\end{array}$ \\
\hline 11.7 .2016 & $\begin{array}{l}\text { ANT berichtet, dass in Turkmenistan neue Vorschriften für Geldüberweisungsdienste wie Western Union in } \\
\text { Kraft getreten sind. Demnach muss der Empfänger nachweisen, in welcher Beziehung er zum Absender steht, der } \\
\text { Absender muss belegen, wie er das zu versendende Geld erworben hat. }\end{array}$ \\
\hline 12.7.2016 & $\begin{array}{l}\text { Eine Studie der US-amerikanischen Prison Policy Initiative stellt fest, dass Turkmenistan mit } 583 \text { Häftlingen je } \\
100.000 \text { Einwohner nach den USA ( } 693 \text { Häftlinge) weltweit die zweithöchste Quote von Inhaftierten hat. }\end{array}$ \\
\hline 15.7.2016 & ne Ausweitung der Förderung mittels neuer Technik aus Chin \\
\hline
\end{tabular}




\begin{tabular}{|l|l|}
\hline 15.7.2016 & $\begin{array}{l}\text { Präsident Berdymuchammedow nimmt im Rahmen einer erweiterten Kabinettssitzung erneut zahlreiche Neube- } \\
\text { setzungen öffentlicher Ämter vor, so werden Mammetnijas Nurmammedow zum neuen Minister für Kommunal- } \\
\text { wirtschaft, Dowran Saburow zum Chef der staatlichen Fluglinie Türkmenhowayollary und Atakuli Tatow zum } \\
\text { Direktor des für den Bau der TAPI-Pipeline verantwortlichen Staatskonzerns Turkmenneftegazstroi ernannt. } \\
\text { Ihre Vorgänger waren wegen schwerwiegender Nachlässigkeiten in ihrer Amtsführung entlassen worden. Präsi- } \\
\text { dent Berdymuchammedow gibt zudem die Auflösung des Ministeriums für Öl und Gas bekannt, dessen Aufga- } \\
\text { ben auf eine neu gebildete Kabinettsabteilung unter Leitung von Vize-Premier Jagschygeldy Kakajew sowie die } \\
\text { Staatskonzerne Turkmengaz und Turkmennebit übertragen werden. }\end{array}$ \\
\hline 16.7.2016 & $\begin{array}{l}\text { Die bisherige Türkisch-Turkmenische Universität wird auf Anweisung des Präsidenten in die Universität für Inge- } \\
\text { nieurtechnologien umgebildet. }\end{array}$ \\
\hline 16.7.2016 & $\begin{array}{l}\text { Die staatliche Zeitung Nejtralnyj Turkmenistan meldet, dass das BIP-Wachstum im ersten Halbjahr 2016 gegen- } \\
\text { über dem Vorjahreszeitraum um drei Prozentpunkte auf 6,1\% gefallen ist. }\end{array}$ \\
\hline 18.7.2016 & $\begin{array}{l}\text { In Aschchabad erscheint der achte Band der von Präsident Berdymuchammedow verfassten Reihe zu den Heil- } \\
\text { pflanzen Turkmenistans. }\end{array}$ \\
\hline 18.7.2016 & $\begin{array}{l}\text { ANT meldet unter Berufung auf regierungsnahe Quellen, dass der Sohn von Präsident Berdymuchammedow, } \\
\text { Serdar, eine neu geschaffene Position im Außenministerium übernommen habe. }\end{array}$ \\
\hline 20.7.2016 & $\begin{array}{l}\text { Nach dem mutmaßlichen Terroranschlag in Almaty schließt Turkmenistan für fünf Tage einseitig seine Grenze } \\
\text { zu Kasachstan. }\end{array}$ \\
\hline 20.7.2016 & $\begin{array}{l}\text { Die Nachrichtenagentur Reuters berichtet, dass der Zugang zu Devisen für Privatunternehmer und Firmen wei- } \\
\text { ter eingeschränkt wurde. Die am Bau der TAPI-Pipeline und der Asiatischen Spiele für Hallen- und Kampfsport- } \\
\text { arten beteiligten Unternehmen sind von den neuen Regelungen ausdrücklich ausgenommen. }\end{array}$ \\
\hline 21.7.2016 & $\begin{array}{l}\text { Präsident Berdymuchammedow und die neue Leiterin des OSZE-Zentrums in Aschchabad, Natalja Drosd, bespre- } \\
\text { chen die zukünftige bilaterale Zusammenarbeit vor allem im Bereich Sicherheitspolitik. }\end{array}$ \\
\hline
\end{tabular}

\section{Usbekistan}

\begin{tabular}{|c|c|}
\hline 27.6.2016 & $\begin{array}{l}\text { Taschkent werden 1,43 t Drogen, davon } 145 \mathrm{~kg} \text { Heroin und } 665 \mathrm{~kg} \text { Opium, verbrannt, die von den Sicher- } \\
\text { itskräften beschlagnahmt worden waren. Insgesamt wurden } 2015 \text { in Usbekistan 2,5 t Drogen beschlagnahmt. }\end{array}$ \\
\hline 28.6.2016 & $\begin{array}{l}\text { Die Generalstaatsanwaltschaft dementiert Berichte, dass der stellvertretende Premierminister und Chef der Usaw- } \\
\text { tosanoat AG, Ulugbek Rusikolow, unter Hausarrest gestellt sei. }\end{array}$ \\
\hline 29.6.2016 & nter den Opfern des Anschlags auf den Flughafen von Istanbul sind zwei usbekische Staatsbürger. \\
\hline 30.6 .2016 & $\begin{array}{l}\text { Türkische Medien melden, dass der Anschlag auf den Flughafen von Istanbul von einem russischen Staatsbürger } \\
\text { tschetschenischer Nationalität, einem Kirgisen und einem Usbeken verübt wurde. }\end{array}$ \\
\hline 30.6 .2016 & $\begin{array}{l}\text { Während eines im Fernsehen übertragenen Treffens Präsident Islam Karimows mit Farmern im Bezirk Termes } \\
\text { (Gebiet Suchandarja), wendet sich Karimow gegen einen Führerkult um seine Person. }\end{array}$ \\
\hline 1.7.2016 & $\begin{array}{l}\text { Die ADB bewilligt einen Kredit in Höhe von } 100 \text { Mio. US-Dollar für mehrere Banken zur Finanzierung von } \\
\text { kleinen Unternehmen. }\end{array}$ \\
\hline 1.7. & $\begin{array}{l}\text { Ab sofort ist für Bürger Usbekistans die Summe, die sie mit sogenannten Konversionskarten in Devisen von Auto- } \\
\text { maten abheben können, auf } 300 \text { US-Dollar im Monat bzw. } 100 \text { US-Dollar am Tag begrenzt. Fast zeitgleich wird } \\
\text { bekannt, dass mit WOY-WO nunmehr eine Internetplattform zur Verfügung steht, über die im Internet bestellte } \\
\text { Waren mit Uzcards bezahlt werden kann. }\end{array}$ \\
\hline 1.7.2016 & $\begin{array}{l}\text { Der jährliche »Trafficking in Persons«-Bericht des U.S. State Departments führt Usbekistan (und Turkmenistan) als } \\
\text { Staaten auf, deren Regierungen kaum Anstrengungen gegen den weitverbreiteten Menschenhandel unternehmen. }\end{array}$ \\
\hline 2.7.2016 & $\begin{array}{l}\text { Der usbekische Dienst von RFE/RL meldet, dass am Mittag der stellvertretende Chef der inneren Verwaltung } \\
\text { des Gebiets Kaschkdadarja, Dschachangir Tschinalijew, von Unbekannten durch Messerstiche verletzt wurde. }\end{array}$ \\
\hline 5.7.2016 & $\begin{array}{l}\text { Die Behörden wenden sich gegen Panik in den sozialen Netzwerken über das Auftauchen von Milzbrandfällen in } \\
\text { Taschkent, tatsächlich stände nur ein Verdachtsfall unter Quarantäne. }\end{array}$ \\
\hline 5.7.2016 & $\begin{array}{l}\text { Der Staatsanwalt des Bezirks Tschinas (Gebiet Taschkent), Bechsod Mirsoatow, wird im Zusammenhang mit den } \\
\text { Ermittlungen gegen die Finanzpyramide von Achmad Tursunbajew entlassen. }\end{array}$ \\
\hline
\end{tabular}




\begin{tabular}{|c|c|}
\hline 11.7.2016 & $\begin{array}{l}\text { e russische Nachrichtenagentur RIA Nowosti meldet, dass der ehemalige Chef der für Ein-und Ausreise sowie } \\
\text { aatsbürgerschaftsfragen zuständigen Behörde des Gebiets Fergana, Odildschon Soljew, zu einer sechsjährigen } \\
\text { eiheitsstrafe wegen Annahme von Bestechungsgeldern für die Ausfertigung von Ausreisepapieren verurteilt } \\
\text { Irde. Die Begünstigten sollen nach Syrien gegangen sein. }\end{array}$ \\
\hline 11. & $\begin{array}{l}\text { er usbekische Dienst von RFE/RL meldet, dass Premier Schawkat Mirsijojew mehr als } 30 \text { Mitarbeiter von sani- } \\
\text { r-epidemiologischen Stationen im Bezirk Utschkuprik (Gebiet Fergana) beauftragt habe, in Privathäusern Kuh- } \\
\text { Ing zu sammeln, der zur Düngung von Feldern verwendet werden soll. Wegen Brennstoffmangels nutzen die } \\
\text { ewohner den Dung zum Kochen und Heizen. }\end{array}$ \\
\hline 11.7 & $\begin{array}{l}\text { ach Angaben des Automobile Manufacturers Committee of the Association of European Businesses (AEB) hat } \\
\text { s usbekisch-US-amerikanische Joint Venture GM Uzbekistan in der ersten Jahreshälfte } 20168.574 \text { Autos in } \\
\text { sssland verkauft, d. i. 17,2\% weniger als im Vergleichszeitraum des Vorjahres, für den Juni waren es mit } 1.136 \\
\text { gar 34,5\% weniger. }\end{array}$ \\
\hline 11.7 & $\begin{array}{l}\text { wohner von zwei an Usbekistan grenzenden Bezirken der afghanischen Provinz Balch beschuldigen usbekische } \\
\text { enzer, in den vergangenen Monaten aus ihren Dörfern junge Männer entführt zu haben, berichtet Gandhara. }\end{array}$ \\
\hline 12.7 & $\begin{array}{l}\text { ne Delegation des russischen Landwirtschaftsministeriums unter Leitung des stellvertretenden Ressortchefs } \\
\text { rgej Lewin trifft zum Besuch der ersten Internationalen Obst- und Gemüsemesse in Taschkent ein. Beide Seite } \\
\text { reinbaren die Erarbeitung vereinfachter Regeln für den Import usbekischen Obsts und Gemüses in die RF. }\end{array}$ \\
\hline 12. & $\begin{array}{l}\text { ut Bericht des usbekischen Dienstes von RFE/RL haben die Behörden der Menschenrechtsorganisation Esgu- } \\
\text { (Nächstenliebe) den Besuch von mehreren inhaftierten Menschenrechtlern und Journalisten erlaubt, der NGO } \\
\text { len aber die finanzielle Mittel, um die dafür erforderlichen Reisen zu finanzieren. }\end{array}$ \\
\hline 13.7 & $\begin{array}{l}\text { as Komitee für Religionsangelegenheiten gibt das Erscheinen eines Sammelba } \\
\text { chtsgutachten) von Gelehrten aus Usbekistan, Ägypten und Syrien gegen Extre }\end{array}$ \\
\hline 14.7 & $\begin{array}{l}\text { zzeta.uz meldet das Erscheinen zweier neuer Präsident Karimow zugeschriebener Werke mit den Titeln: „Ein } \\
\text { lk, das die Luft der Freiheit atmet« und „Das Volk von Kaschkadarja, gestählt in den Prüfungen des Lebens, } \\
\text { zur Erreichung höchster Ziele fähig«. }\end{array}$ \\
\hline 14.7 & $\begin{array}{l}\text { N-Radio meldet, dass die seit } 2000 \text { auf der Liste des UNESCO-W } \\
\text { hachrisabs (Gebiet Kaschkadarja) durch Abriss historischer Gebäude }\end{array}$ \\
\hline 14.7 & $\begin{array}{l}\text { I usbekische Dienst von RFE/RL berichtet, dass in Russland im Zusammenhang mit den Ermittlungen } \\
\text { gen den ehemaligen Generaldirektor von GM Uzbekistan und stellvertretenden Vorsitzenden der Vertriebs- } \\
\text { ellschaft Uzawtosanoat, Tochirdschon Dschalilow, und weitere Mitarbeiter des Autokonzerns } 17.000 \text { Autos } \\
\text { chlagnahmt wurden. }\end{array}$ \\
\hline 14.7 & $\begin{array}{l}\text { s Zollkomitee des Gebiets Fergana meldet die Entdeckung von } 468 \text { Saigahörnern und } 170 \text { Saigafellen im Wert } \\
\text { n ca. } 150 \text { Mio. Sum ( } 50.000 \text { US-Dollar), die außer Landes geschmuggelt werden sollten. }\end{array}$ \\
\hline 15. & $\begin{array}{l}\text { r usbekische Dienst von RFE/RL berichtet, dass im Bezirk Jakkabag (Gebiet Kaschkadarja) auf Ano } \\
\text { Serwaltungschefs wegen der bisherigen Nichterfüllung des Ablieferungsplans für Weizen die Ernte un }\end{array}$ \\
\hline 15.7.2016 & \\
\hline 15.7 .2016 & $\begin{array}{l}\text { as U.S. Central Command hat den Grenztruppen sechs MAN-LKW geschenkt, meldet die Website der US- } \\
\text { otschaft. } 2015 \text { hatten sie bereits } 20 \text { Wagen dieses Typs erhalten. }\end{array}$ \\
\hline 18.7.2016 & $\begin{array}{l}\text { e UNESCO nimmt den in Usbekistan, Kirgistan und Kasachstan gelegenen westlichen Tien-Schan in die } \\
\text { ste der Welt-Naturerbes auf. }\end{array}$ \\
\hline 18.7.2016 & $\begin{array}{l}\text { as Ministerkabinett beschließt weitgehende Umstrukturierungen der Verwaltung der Akademie der Wissen- } \\
\text { haften, zuvor waren bereits mehrere Institute Taschkenter Universitäten angegliedert worden. }\end{array}$ \\
\hline 19.7.2016 & $\begin{array}{l}\text { In Reaktion auf den Vertragsabschluss Tadschikistans mit der italienischen Salini Impregilo S.p.A über den Bau } \\
\text { des Wasserkraftwerkes Rogun bringt Premier Mirsijojew in einem Brief an seinen tadschikischen Amtskollegen } \\
\text { Kohir Rasulsoda erneut die Bedenken Usbekistans gegen das Projekt zum Ausdruck. }\end{array}$ \\
\hline 19.7. & d Gemüse-Messe des \\
\hline
\end{tabular}




\begin{tabular}{|l|l|}
\hline 19.7.2016 & $\begin{array}{l}\text { Amnesty International macht in einer Stellungnahme bekannt, dass Russland am 1.7. entgegen einstweiliger } \\
\text { Beschlüsse des Europäischen Gerichtshofes für Menschenrechte vom 28.6. den usbekischen Staatsbürger Olim } \\
\text { Ochilow zwangsweise nach Usbekistan ausgeliefert hat. Ochilow hatte politisches Asyl in der RF beantragt. }\end{array}$ \\
\hline 20.7.2016 & $\begin{array}{l}\text { Der französische Staatssekretär für Außenhandel und Tourismusförderung, Matthias Fekl, trifft zur Teilnahme } \\
\text { an der sechsten Sitzung der Zwischenregierungskommission für Zusammenarbeit in Handel und Wirtschaft zwi- } \\
\text { schen Frankreich und Usbekistan in Taschkent ein. }\end{array}$ \\
\hline 20.7.2016 & $\begin{array}{l}\text { Der usbekische Dienst von RFE/RL berichtet, dass in diesem Jahr Absolventen religiöser Schulen (Medressen) } \\
\text { der Hochschulzugang verwehrt werde. }\end{array}$ \\
\hline 20.7.2016 & $\begin{array}{l}\text { Nach Angaben des staatlichen Komitees für Statistik ist die Bevölkerung des Landes in der ersten Jahreshälfte um } \\
\text { 0,7\% gewachsen und betrug am 1.7.2016 31,8 Mio. Menschen. }\end{array}$ \\
\hline 20.7.2016 & $\begin{array}{l}\text { Uzmetronom berichtet, dass beim Usbekischen Metallurgischen Kombinat in Bekabad (Gebiet Taschkent) meh- } \\
\text { rere Mitglieder der Firmenführung im Zusammenhang mit Unterschlagung von Geldern bei der Realisierung } \\
\text { von Investitionsprojekten entlassen wurden }\end{array}$ \\
$\begin{array}{l}\text { Ein Gericht in Amsterdam verurteilt die in Gibraltar registrierte Firma Takilant Ltd. von Präsidententochter Gul- } \\
\text { nara Karimowa zur Rückzahlung von 123 Mio. Euro sowie einer Geldbuße von 1,6 Mio. Euro wegen Annahme } \\
\text { von Bestechungsgeldern der Telekommunikationsfirmen Vimpelcom Ltd. und Telia AB für den Zugang zum } \\
\text { usbekischen Markt. Die Staatsanwaltschaft hatte die Beschlagnahmung von mehr als 300 Mio. Euro sowie eine } \\
\text { Strafzahlung von fast 5 Mio. Euro beantragt. }\end{array}$ \\
\hline 22.7.2016 & $\begin{array}{l}\text { Ein Gericht im Gebiet Namangan verurteilt sieben Männer zu fünf- bis neunjährigen Freiheitsstrafen, die geplant } \\
\text { haben sollen, nach Syrien auszureisen und sich dem IS anzuschließen. }\end{array}$ \\
\hline 22.7.2016 & $\begin{array}{l}\text { Das Ministerkabinett beschließt erste Maßnahmen zur Schaffung eines Saiga-Naturschutzgebietes in den Bezir- } \\
\text { ken Muinak und Kungrad (Autonome Republik Karakalpakstan). }\end{array}$ \\
\hline
\end{tabular}

Sie können die gesamte Chronik seit 2008 auch auf <http://www.laender-analysen.de/zentralasien/> unter dem Link »Chronik«lesen.

Redaktionsassistenz: Henryk Alff

Satz: Matthias Neumann

Zentralasien-Analysen-Layout: Matthias Neumann, nach einen Konzept von Cengiz Kibaroglu, mit einer Grafik von Sebastian Klüsener Alle Ausgaben der Zentralasien-Analysen sind mit Themen- und Autorenindex archiviert unter www.laender-analysen.de

ISSN 1866-2110 @ 2016 by Deutsche Gesellschaff für Osteuropakunde e.V. und Forschungsstelle Osteuropa, Bremen 


\section{Kostenlose E-Mail-Dienste der Forschungsstelle Osteuropa und ihrer Partner auf www.laender-analysen.de}

Die Länder-Analysen bieten regelmäßig im kostenlosen Abonnement kompetente Einschätzungen aktueller politischer, wirtschaftlicher, sozialer und kultureller Entwicklungen in Ostmitteleuropa und der GUS. Sie machen das Wissen, über das die wissenschaftliche Forschung in reichem Maße verfügt, für Politik, Wirtschaft, Medien und die interessierte Öffentlichkeit verfügbar. Autoren sind internationale Fachwissenschaftler und Experten.

Die einzelnen Länder-Analysen werden von der Forschungsstelle Osteuropa an der Universität Bremen und der Deutschen Gesellschaft für Osteuropakunde jeweils mit unterschiedlichen Partnern und Sponsoren herausgegeben. Die Redaktionen der Länder-Analysen bestehen aus Wissenschaftlern mit langjähriger Forschungserfahrung.

Die Länder-Analysen bieten regelmäßig Kurzanalysen zu aktuellen Themen, ergänzt um Grafiken und Tabellen sowie Dokumentationen. Zusätzlich gibt es eine Chronik aktueller Ereignisse. Alle Länder-Analysen sind auch mit Archiv und Indizes online verfügbar unter $<$ www.laender-analysen.de $>$.

\section{Belarus-Analysen}

Erscheinungsweise: zweimonatlich

Abonnement unter: <http://www.laender-analysen.de/belarus/>

\section{Caucasus Analytical Digest}

In englischer Sprache. Erscheinungsweise: monatlich

Abonnement unter: <http://www.css.ethz.ch/en/publications/cad.html>

\section{Polen-Analysen}

Erscheinungsweise: zweimal monatlich

Abonnement unter: <http://www.deutsches-polen-institut.de/newsletter/polen-analysen/>

\section{Russland-Analysen}

Erscheinungsweise: zweiwöchentlich

Abonnement unter: <http://www.laender-analysen.de/russland/>

\section{Russian Analytical Digest}

In englischer Sprache. Erscheinungsweise: zweimal monatlich

Abonnement unter: <http://www.css.ethz.ch/en/publications/rad.html>

\section{Ukraine-Analysen}

Erscheinungsweise: zweimal monatlich

Abonnement unter: <http://www.laender-analysen.de/ukraine/>

\section{Zentralasien-Analysen}

Erscheinungsweise: monatlich

Abonnement unter: <http://www.laender-analysen.de/zentralasien/>

\section{Bibliographische Dienste}

Die Bibliographien informieren über englisch- und deutschsprachige Neuerscheinungen zu Belarus, Russland, Ukraine sowie zu den zentralasiatischen und kaukasischen Staaten. Erfasst werden jeweils die Themenbereiche Politik, Außenpolitik, Wirtschaft und Soziales.

Erscheinungsweise: viermal jährlich

Abonnement unter: <http://www.laender-analysen.de/bibliographies/belarus.php $>$, <http://www.laender-analysen. de/bibliographies/russia.php>, <http://www.laender-analysen.de/bibliographies/ukraine.php>, <http://www.laenderanalysen.de/bibliographies/caucasus_ca.php> 